\title{
Development trajectory for the temporal and spatial evolution of the resilience of regional tourism environmental systems in 14 cities of Gansu Province, China
}

\author{
Xiuping Yang ${ }^{1}$ D $\cdot$ Dacheng Zhang $^{2} \cdot$ Lili Liu $^{1} \cdot$ Jing Niu ${ }^{1} \cdot$ Xiaobo Zhang $^{1} \cdot$ Xiaoyun Wang $^{1}$ \\ Received: 9 October 2020 / Accepted: 11 June 2021 / Published online: 6 July 2021 \\ (C) The Author(s), under exclusive licence to Springer-Verlag GmbH Germany, part of Springer Nature 2021
}

\begin{abstract}
The rapid development of the urban economy in China and the accompanying income growth experienced by urban residents have increased demand for tourism and leisure, which has brought pressure on the urban tourism environment system (UTES), making the contradiction between tourism economic development and the ecological environment increasingly acute. While seeking to rationalize the economic, social, and ecological benefits of tourism, reducing the fragility of the UTES and improving its anti-interference and recovery capabilities have become attracted significant attention from scholars in China and elsewhere. This paper establishes a definition of resilience for an UTES and constructs an evaluation index system for it in terms of the social, economic, and ecological environments. It also establishes an entropy weight-TOPSIS resilience evaluation model to measure resilience in regional systems, using ArcGIS to analyze the standard deviation ellipse and center of the gravity track of the resilience. System dynamics was used to construct diagrams of causal relationships and stock flow for the constituent elements of UTES to show the mechanisms that promote its resilience. This paper investigates 14 cities of Gansu Province in particular to simulate the resilience model of a regional system.
\end{abstract}

Keywords Tourism environmental system $\cdot$ Resilience $\cdot$ System dynamics $\cdot$ Development trajectory $\cdot$ Spatial evolution $\cdot$ Region

\section{Introduction}

Urbanization has accelerated the formation of urban regionalization and urban agglomerations. The degree to which city scale matches tourism growth affects the cities' functioning and effective regional cooperation among them. Growing uncertainty in regional UTES and the long-term accumulation of chronic urban diseases expose such systems to various uncertain risks. This paper provides a new research perspective for the sustainable development of regional tourism. Improving resilience in a regional UTES is an effective way to promote

Responsible Editor: Philippe Garrigues

Xiuping Yang

yangxp789@163.com

1 Department of Economy and Management, Lanzhou University of Technology, Lanzhou 730050, China

2 School of Business Administration, Xuzhou College of Industrial Technology, Xuzhou 221140, China sustainable development in urban tourism and coordinate its development. It also provides a new direction for urban management and development research in the twenty-first century, which requires in-depth study.

Tourism destinations are vulnerable, so black-swan incidents like the outbreak of the novel coronavirus disease in early 2020, which led to significant downward pressure on the economy. Exploring resilience in UTES and increasing weight of the tourism economy in a destination system have attracted increased attention and become focal points for the transformation of the national economy even during an epidemic, and it can also effectively bring the destination tourism environment system to cope with external factors.

Gansu Province is an important node of China's "Silk Road." It is rich in natural, historical, and cultural tourism resources. Under the background of global tourism, tourism experience is further deepened. However, the development of tourism in Gansu Province not only drives the local economic development, but also brings a series of environmental problems. To a large extent, the tourism development of some cities is at the expense of environmental quality, which 
aggravates the vulnerability of urban tourism ecological environment system and damages the sustainable development of urban tourism.

Urban tourism environment system is a nonlinear and dynamic complex system composed of social, economic, and ecological subsystems. The evolution process of urban tourism environment system resilience is not only affected by the changes of ecology, resources, and environment, but also by the interference of tourism development and tourist activities, as well as the influence of the changes of local economic and social policies. The interaction of many factors makes the urban tourism environmental system resilience and its evolution process more complex.

Resilience in a regional tourism environment system is a key concern of tourism geography, and it is also the most important new direction for regional tourism development in the twenty-first century, requiring in-depth study. The development of the tourism economy of a regional tourism destination depends upon the exploration of the temporal and spatial evolution of its resilience in a specific area, and investigations in this area will help realize the goal of developing a harmonious society in the tourism destination.

\section{Literature review}

A UTES is the foundation for tourism development, and developing a tourism economy based on environmental protection is a feasible path for achieving sustainable and balanced growth in a tourism destination (Marsiglio 2015). This topic has received extensive attention from scholars in China and elsewhere, who draw on work in multiple subjects to clarify the impact that tourism activities have on the tourism environment and determine how the vital and sustainable development of destination tourism is to be promoted in an environmentally friendly manner. There have been useful discussions in theoretical and industrial circles on related issues. Study of the elements of the tourism environment has mostly focused on the economic environment, social and cultural environment, political environment, natural environment, and so on, in relation to tourism (Kushi 2011). Study on tourism environment systems has focused on tourism impacts (Shahgerdi and Rezapouraghdam 2016; Pavlovi et al. 2020), environmental carrying capacity (Middleton and Hawkins 2013), environmental ethics ('Nikazachenko et al. 2018; Dharmawan 2013), environmental quality (Ouattara et al. 2019), and other aspects of tourism and the environment. For the examination of tourism issues related to the environmental system, the methods of ecological footprint assessment (Wall 2019), image analysis (OBIA), digital elevation model analysis (ASTER DEM) (Dey et al. 2018), questionnaire surveys (Katircioglu et al. 2019), statistical analyses method (Jurigová 2016), agent modeling (Amelung et al. 2016), OLS (Singha and Singha
2012), cointegration analyses and Granger causality tests (Lee et al. 2009), vector autoregressive (VAR) models (Malliga 2014), network analysis (ANP) (Bramwell 2010), and others have been used for the study of issues related to tourism environmental systems (Cheng and Jia 2020; Cong et al. 2019). At the same time, discussion of the relationship between the tourism environment system and related systems is gradually becoming more prevalent (Butler 1991; Made 2019), resulting in the active promotion of the sharing of the tourism environment in terms of multiple destinations. Scholars in China and elsewhere have gradually clarified the research topics of the tourism environment system using gradually enriched quantitative methods, and these have played an important role in enriching tourism management theories. In the literature of China and elsewhere, the research results are analyzed from multiple angles, with clear research aims and scopes. They often present interdisciplinary characteristics, with econometric methods, social network analyses, and geographical approaches that are increasingly integrated. Here, quantitative methods are combined with tourism purposes, and empirical research shows an increasingly expansive trend in development trend.

The study of resilience began in the 1970s. Holling applied the theory of resilience to ecology to discuss disturbances caused by adjustments to system structures (Holling 1973). Following this, scholars investigated disaster resilience, community resilience, and economic resilience (Nabin 2014; Lew and $\mathrm{He} 2016$ ). It was proposed that resilience in tourist destinations exhibits exposure, sensitivity, and adaptability (Calgaro et al. 2014; Strickland-Munro et al. 2010), and researchers carried and investigated the resilience of a destination's ecology, society, and economy (Larsen et al. 2011; Chen and Yang 2011) and showed the necessity for comprehensive and inclusive management plans in tourist destinations (Ghaderi et al. 2015). Research on resilience in tourism destinations was carried out using interviews (Holladay and Powell 2016), structural equation modeling (Wang et al. 2017), early warning technology (Nancy AB et al. 2018), and other methods. Such work is hoped to enhance the resilience on island tourist destinations (Dogru et al. 2019; Banerjee et al. 2018) and in tourist communities (Bangwayo-Skeete and Skeete 2020) and cities (Guo et al. 2018), as well as to promote study of the sustainable development of tourist destinations (Erdmenger 2019). By studying and analyzing resilience at home and abroad, a theoretical framework has been formed for resilience research that focuses mostly on emergencies.

Study of the resilience of regional destination tourism environments remains to be done, whether in China or abroad. Combined with the particularity of regional tourism destinations, analyses of gradual changes in a regional tourism environment system and discussion of the gradual process of the resilience of the destination tourism environment system can 
help accomplish the return of regional tourism development from a focus on quantity to one on improving quality. This represents the main direction of regional tourism development in the twenty-first century, which remains to be studied indepth. This paper draws on theories of social-ecological systems and resilience and investigates the connotation of UTES resilience, taking Gansu Province, China, as its regional background, constructing and measuring the indexes of UTES resilience, analyzing the standard deviation ellipse and trajectory of the center of gravity of the resilience of the urban tourism environment system, building a system dynamics model of the resilience of the UTES using system dynamics theory and simulating the process of its evolution, proposing suggestions for improvements to the resilience of the UTES, and providing a decision-making reference to promote the sustainable development of regional urban tourism.

\section{Theoretical research framework}

\section{Definition of resilience for a regional tourism environment system}

The resilience of a destination tourism environment system has gradually become a paradigm for sustainable development of regional tourism destinations, leading to a new research perspective to examine the balanced development of supply and demand in a regional destination tourism environment system. The resilience of a tourism environment system requires the maintenance of the structure and function of the original system in the face of stress and change. Here, resilience refers to the ability of the economy, society, and ecological environment of a destination to absorb disturbances made up of the combined effects of external disturbances and internal structural changes to maintain a system in its original state or adapt to environmental changes to make a new stable state. In a destination tourism environment system, resilience can be studied in its temporal and spatial characteristics, showing dynamic changes over a specific time span and showing signs of future trends of development. Spatial changes of resilience variables can also be examined, along with the spatial layouts of resilience in a tourism environment system within the region, and the cross-scale correlations between the differences in resilience in tourism environment systems can be explored. Tourism destination life cycle theory indicates that the resilience of a regional tourism environment system can be simulated and predicted, and its adaptive cycle can be roughly divided into four periods. The exploration period of a tourist destination corresponds to the exploitation stage of its resilience. Then, in the development stage of tourism destination development, the growth rate of incoming tourists gradually expands, and the development potential of the resilience of the system must be tapped. In the stable stage, corresponding to the protection stage of the system's resilience, the inflection point of the marginal growth rate of the tourism environment demand appears. When the life cycle of a tourism destination enters its stagnation, decline, or recovery phase, the destination gradually declines, the tourism environment system degrades, and the resilience of the system enters the renewal phase, as shown in Fig. 1.

Pressure is a disturbance factor that affects the resilience of a regional UTES. A tourism system integrates influencing factors to prompt the tourism environment system to promptly recover or re-enter a new state, which may be better or worse than or even completely different from the previous state. The resilience of a regional tourism environment system maintains its stability, develops it into a virtuous circle, stimulates the improvement of the quality of the regional destination tourism environment system, eliminates or reduces pressure on the system caused by multi-subject demand, and promotes a virtuous circle of development to enable a livable and healthy tourist destination. The reorganization, promotion, and learning of the resilience of the regional UTES system can bring a regional tourism environment system to a high level.

The reconstruction of resilience in a tourism environment system is a manifestation of its development and transformation as a destination, and it shows the reshaping of a destination tourism environment system under the influence of the interaction between supply and demand for a tourism environment system, promoting the components of the system's resilience to gradually achieve balance among its contradictions and conflicts. Beginning in the temporal and spatial evolution of the resilience of the regional destination tourism environment system, the spatial reconstruction of a future destination tourism environment system should be discussed, and the resilience of a regional system should be measured in relation to the dynamic characteristics of the adaptive cycle of resilience to allow dynamic monitoring of the resilience of a tourist environment system of destinations.

Resilience theory can be source of new ideas for the development of a regional tourism economy. Its application to the study of regional tourism environmental systems indicates a new understanding of the realization of intra-generational and inter-generational equity in sustainable development on the part of scholars. In the study of tourism resilience, the beneficiaries and fairness of the destination tourism environment system are considered, theoretical research frameworks to describe the resilience of a regional tourism environment system are constructed, and theories of regional sustainable development are enriched. For a given region, discussing the evolution of resilience of the tourism environment system of a regional tourism destination and realizing the mutual promotion of an environment system of a tourism destination and multi-subjects will help realize the joint construction and sharing of tourism destinations. Based on the connotation of the resilience of the 


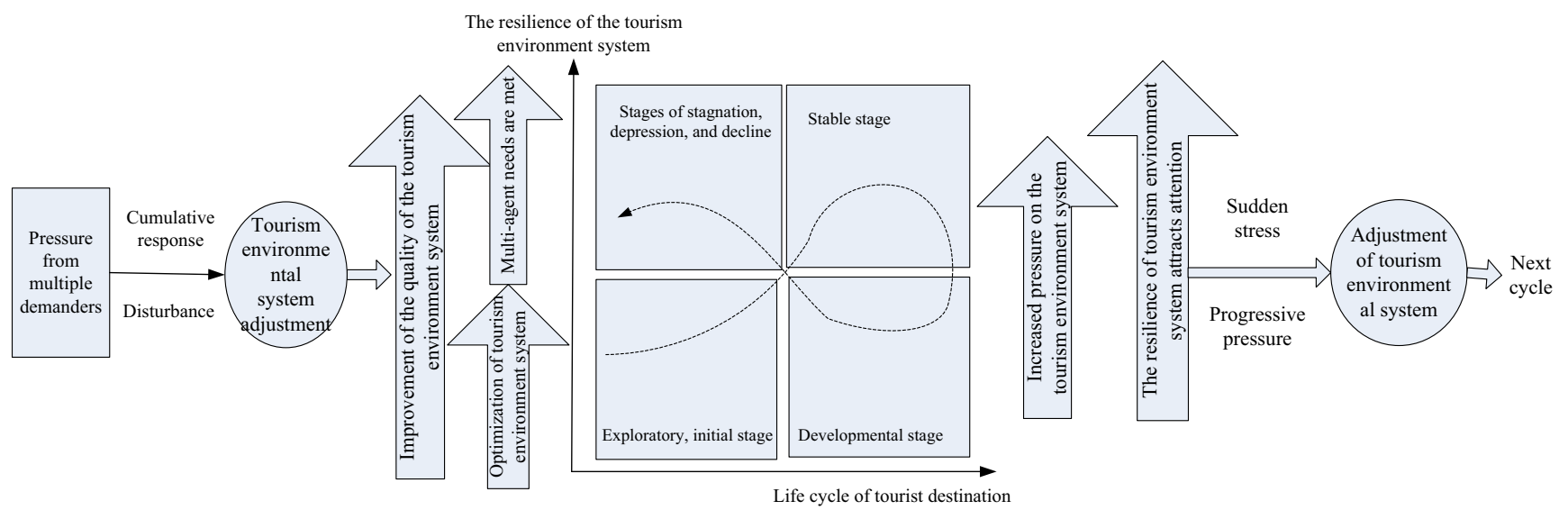

Fig. 1 Adaptive cycle in the evolution of resilience of an UTES

tourism environment system resilience, the research framework of this article is formed, as shown in Fig. 2.

\section{Evaluation model of resilience in a tourism environmental system}

The resilience of regional tourism environment systems has been extensively studied from scholars in China and elsewhere. The construction of an effective evaluation model of the resilience of a regional tourism environment system is attracting greater focus in academic and policy circles.

\section{Index system for the resilience of tourism environment system}

Incorporating disturbance factors of the urban tourism environment system in its economic, social, and ecological aspects, this article constructs an indicator system of the resilience of a regional system. Using SPSS statistical software, the elements of the resilience of an urban system are analyzed, and an index system of the resilience of a regional system are determined through a reliability test of the elements of the resilience of a tourism environment system, as shown in Table 1. The resilience of the natural environment system at a tourism destination is the foundation of its resilience. Relying on the ecological resources of the tourism environment system provided by the natural environment and resources of the multi-subjects, the experience of the multisubjects in the tourism destination regarding the tourism environment is enhanced, as is the public health of the multisubjects. The indicators of the resilience of the tourism economic environment system provide economic support for the development of its environment. The resilience of the social environment system is the core of the development as a

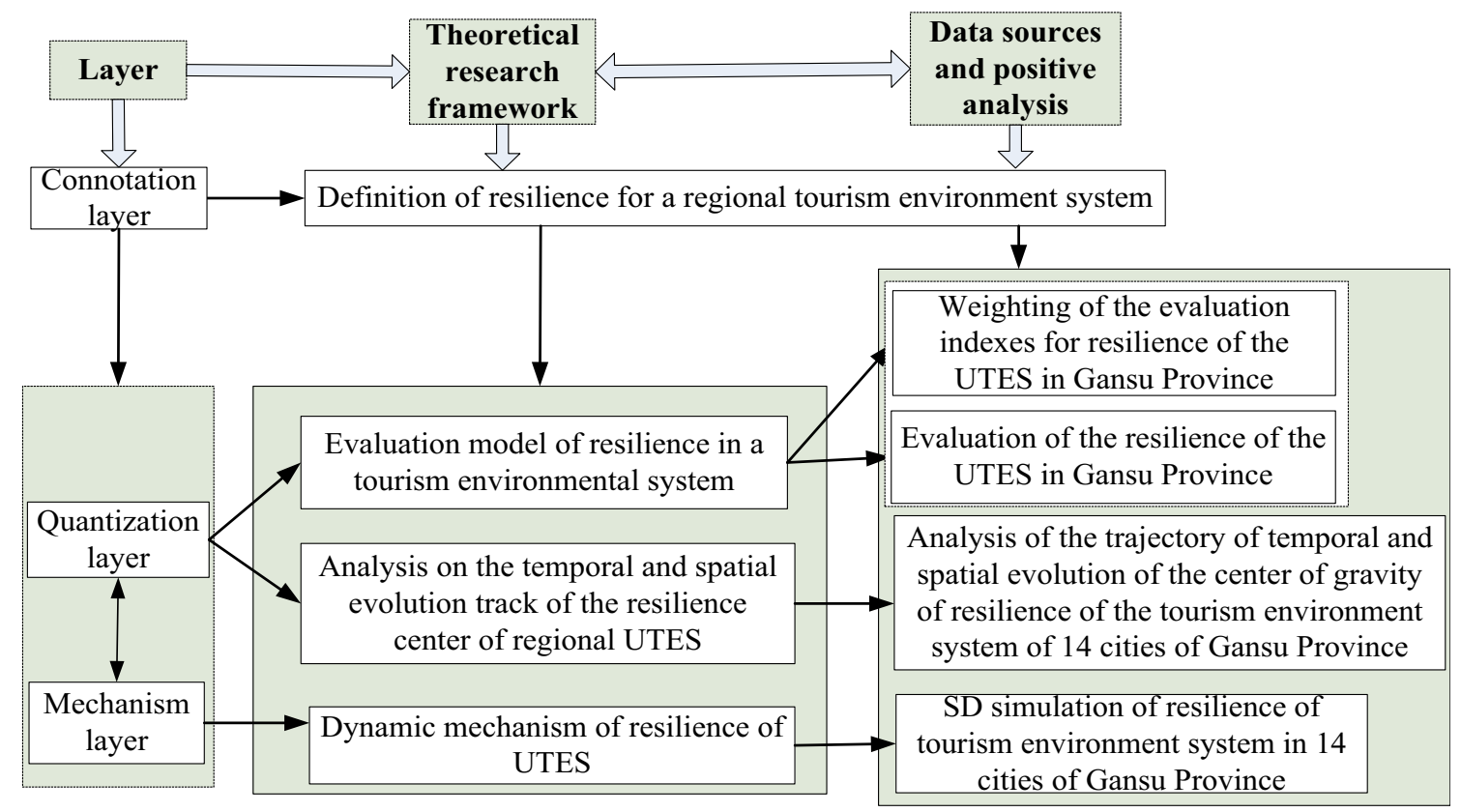

Fig. 2 The structure of the article 
Table 1 Evaluation index system for resilience in an urban tourism environment system

\begin{tabular}{|c|c|c|c|c|}
\hline Subsystem & Index & Unit & Indicator meaning & $\begin{array}{l}\text { Indicator } \\
\text { attributes }\end{array}$ \\
\hline \multirow{14}{*}{$\begin{array}{l}\text { Tourism economic } \\
\text { environment } \\
\text { TEE }\end{array}$} & Total tourism income per capita $\mathrm{TEE}_{1}$ & Yuan & Total tourism income/total population & + \\
\hline & Tourism income growth rate $\mathrm{TEE}_{2}$ & $\%$ & $\begin{array}{l}\text { Increase in' tourism income/last year's } \\
\text { tourism income*100 }\end{array}$ & + \\
\hline & Tourism income as a percentage of GDP $\mathrm{TEE}_{3}$ & $\%$ & Tourism income/GDP*100 & - \\
\hline & $\begin{array}{l}\text { The proportion of inbound tourism revenue to total } \\
\text { tourism revenue } \mathrm{TEE}_{4}\end{array}$ & $\%$ & $\begin{array}{l}\text { Inbound tourism revenue/total tourism } \\
\text { income*100 }\end{array}$ & - \\
\hline & $\begin{array}{l}\text { The proportion of inbound tourists to the total } \\
\text { number of tourists } \mathrm{TEE}_{5}\end{array}$ & $\%$ & $\begin{array}{l}\text { Number of inbound tourists/total } \\
\text { number of tourists*100 }\end{array}$ & - \\
\hline & $\begin{array}{l}\text { Proportion of employees in the tertiary industry } \\
\text { TEE }_{6}\end{array}$ & $\%$ & $\begin{array}{l}\text { Number of people engaged in the } \\
\text { tertiary industry/number of } \\
\text { employees in the three } \\
\text { industries*100 }\end{array}$ & + \\
\hline & Foreign economic dependence $\mathrm{TEE}_{7}$ & $\%$ & $\begin{array}{l}\text { Degree of dependence on foreign } \\
\text { economy, total foreign import and } \\
\text { export/regional gross national } \\
\text { product*100 }\end{array}$ & - \\
\hline & GDP per capita $\mathrm{TEE}_{8}$ & Yuan & GDP/total population & + \\
\hline & Industrial structure diversity index $\mathrm{TEE}_{9}$ & - & $\begin{array}{l}\text { Degree of diversification of industrial } \\
\text { structure }\end{array}$ & + \\
\hline & Social investment in fixed assets $\mathrm{TEE}_{10}$ & 100 million yuan & $\begin{array}{l}\text { Social investment in fixed assets for } \\
\text { the year }\end{array}$ & + \\
\hline & Urban-rural disposable income ratio $\mathrm{TEE}_{11}$ & - & $\begin{array}{l}\text { Per capita disposable income of urban } \\
\text { residents/per capita disposable } \\
\text { income of rural residents }\end{array}$ & - \\
\hline & Disposable income of urban residents $\mathrm{TEE}_{12}$ & Yuan & $\begin{array}{l}\text { The freely disposable income of urban } \\
\text { residents }\end{array}$ & + \\
\hline & $\begin{array}{l}\text { Per capita consumption expenditure of urban } \\
\text { residents } \mathrm{TEE}_{13}\end{array}$ & Yuan & $\begin{array}{l}\text { Urban residents' consumption } \\
\text { expenditure }\end{array}$ & + \\
\hline & Per capita retail sales of consumer goods $\mathrm{TEE}_{14}$ & Yuan & $\begin{array}{l}\text { Total retail sales of consumer } \\
\text { goods/total population }\end{array}$ & + \\
\hline $\begin{array}{r}\text { Tourism social } \\
\text { environment }\end{array}$ & You Ju ratio $\mathrm{TSE}_{1}$ & - & $\begin{array}{l}\text { Number of tourists/number of local } \\
\text { residents }\end{array}$ & + \\
\hline \multirow[t]{13}{*}{ TSE } & Grade highway density $\mathrm{TSE}_{2}$ & $\mathrm{~km} / \mathrm{km}^{2}$ & $\begin{array}{l}\text { Total mileage of graded } \\
\text { roads/administrative area }\end{array}$ & + \\
\hline & Passenger turnover $\mathrm{TSE}_{3}$ & $\begin{array}{l}\text { Million } \\
\text { kilometers }\end{array}$ & $\begin{array}{l}\text { Within a certain period of time, the } \\
\text { number of passengers } \times \text { mileage }\end{array}$ & + \\
\hline & Engel coefficient of urban residents $\mathrm{TSE}_{4}$ & $\%$ & $\begin{array}{l}\text { Total food expenditure of urban } \\
\text { residents/total household } \\
\text { consumption expenditure }\end{array}$ & - \\
\hline & Electricity consumption per capita $\mathrm{TSE}_{5}$ & $\mathrm{KW} / \mathrm{h}$ & $\begin{array}{l}\text { Electricity consumption/Total } \\
\text { population }\end{array}$ & - \\
\hline & Urban registered unemployment rate $\mathrm{TSE}_{6}$ & $\%$ & $\begin{array}{l}\text { Urban registered unemployed/total } \\
\text { population*100 }\end{array}$ & + \\
\hline & Urbanization rate of permanent population $\mathrm{TSE}_{7}$ & $\%$ & $\begin{array}{l}\text { Number of permanent urban } \\
\text { population/total population*100 }\end{array}$ & + \\
\hline & Fiscal revenue and expenditure ratio $\mathrm{TSE}_{8}$ & $\%$ & $\begin{array}{l}\text { Financial revenue/Financial } \\
\text { expenditure }\end{array}$ & + \\
\hline & $\begin{array}{l}\text { Education expenditure as a proportion of fiscal } \\
\text { expenditure } \mathrm{TSE}_{9}\end{array}$ & $\%$ & $\begin{array}{l}\text { Education expenditure/Financial } \\
\text { expenditure*100 }\end{array}$ & + \\
\hline & $\begin{array}{l}\text { Social security and employment expenditure } \\
\text { accounted for the proportion of fiscal } \\
\text { expenditure } \mathrm{TSE}_{10}\end{array}$ & $\%$ & $\begin{array}{l}\text { Social security and employment } \\
\text { expenditure/financial } \\
\text { expenditure*100 }\end{array}$ & + \\
\hline & Number of doctors per 10,000 people $\mathrm{TSE}_{11}$ & People & $\begin{array}{l}\text { Number of doctors in hospital health } \\
\text { center/total population }\end{array}$ & + \\
\hline & Number of public toilets per 10,000 people $\mathrm{TSE}_{12}$ & Seat & $\begin{array}{l}\text { Number of public toilets/total } \\
\text { population }\end{array}$ & + \\
\hline & Telephone penetration rate $\mathrm{TSE}_{13}$ & $\begin{array}{l}\text { Department } / 100 \\
\text { people }\end{array}$ & $\begin{array}{l}\text { Number of telephones/total } \\
\text { population*100 }\end{array}$ & + \\
\hline & Internet penetration rate $\mathrm{TSE}_{14}$ & $\%$ & $\begin{array}{l}\text { Number of Internet users/total number } \\
\text { of households*100 }\end{array}$ & + \\
\hline
\end{tabular}


Table 1 (continued)

\begin{tabular}{|c|c|c|c|c|}
\hline Subsystem & Index & Unit & Indicator meaning & $\begin{array}{l}\text { Indicator } \\
\text { attributes }\end{array}$ \\
\hline \multirow{12}{*}{$\begin{array}{l}\text { Tourism ecological } \\
\text { environment } \\
\text { TEE }\end{array}$} & Proportion of urban built-up area $\mathrm{TEE}_{1}$ & $\%$ & Urban built-up area/Urban area*100 & + \\
\hline & The population density $\mathrm{TEE}_{2}$ & Person $/ \mathrm{km}^{2}$ & $\begin{array}{l}\text { Total population/land area of } \\
\text { administrative district }\end{array}$ & - \\
\hline & Water supply per capita $\mathrm{TEE}_{3}$ & $\mathrm{~m}^{3}$ & Water supply/total population & + \\
\hline & Industrial waste water discharge $\mathrm{TEE}_{4}$ & $\begin{array}{l}\text { Ten thousand } \\
\text { tons }\end{array}$ & $\begin{array}{l}\text { Industrial waste water discharge/total } \\
\text { population }\end{array}$ & - \\
\hline & Solid waste discharge $\mathrm{TEE}_{5}$ & Ton & Solid waste discharge in the year & - \\
\hline & Sulfur dioxide emissions $\mathrm{TEE}_{6}$ & Ton & Sulfur dioxide emissions for the year & - \\
\hline & Proportion of days with good air quality $\mathrm{TEE}_{7}$ & $\%$ & $\begin{array}{l}\text { Number of days when air quality } \\
\text { reaches level } 2 \text { or above/days in a } \\
\text { year*100 }\end{array}$ & + \\
\hline & Park green area per capita $\mathrm{TEE}_{8}$ & $\mathrm{M}^{2}$ & Park green area/total population & + \\
\hline & Green coverage rate of built-up area $\mathrm{TEE}_{9}$ & $\%$ & $\begin{array}{l}\text { Green coverage area/city built-up } \\
\text { area*100 }\end{array}$ & + \\
\hline & $\begin{array}{l}\text { Comprehensive utilization rate of solid waste } \\
\text { TEE }_{10}\end{array}$ & $\%$ & $\begin{array}{l}\text { Comprehensive utilization of solid } \\
\text { waste/production of solid } \\
\text { waste*100 }\end{array}$ & + \\
\hline & Sewage treatment rate $\mathrm{TEE}_{11}$ & $\%$ & $\begin{array}{l}\text { Sewage treatment volume/domestic } \\
\text { sewage discharge volume*100 }\end{array}$ & + \\
\hline & $\begin{array}{l}\text { Harmless treatment rate of domestic } \\
\text { garbage } \mathrm{TEE}_{12}\end{array}$ & $\%$ & $\begin{array}{l}\text { The amount of domestic garbage } \\
\text { treated in a harmless manner/the } \\
\text { amount of domestic garbage } \\
\text { generated } 100\end{array}$ & + \\
\hline
\end{tabular}

Note: + means positive index, - means inverse index

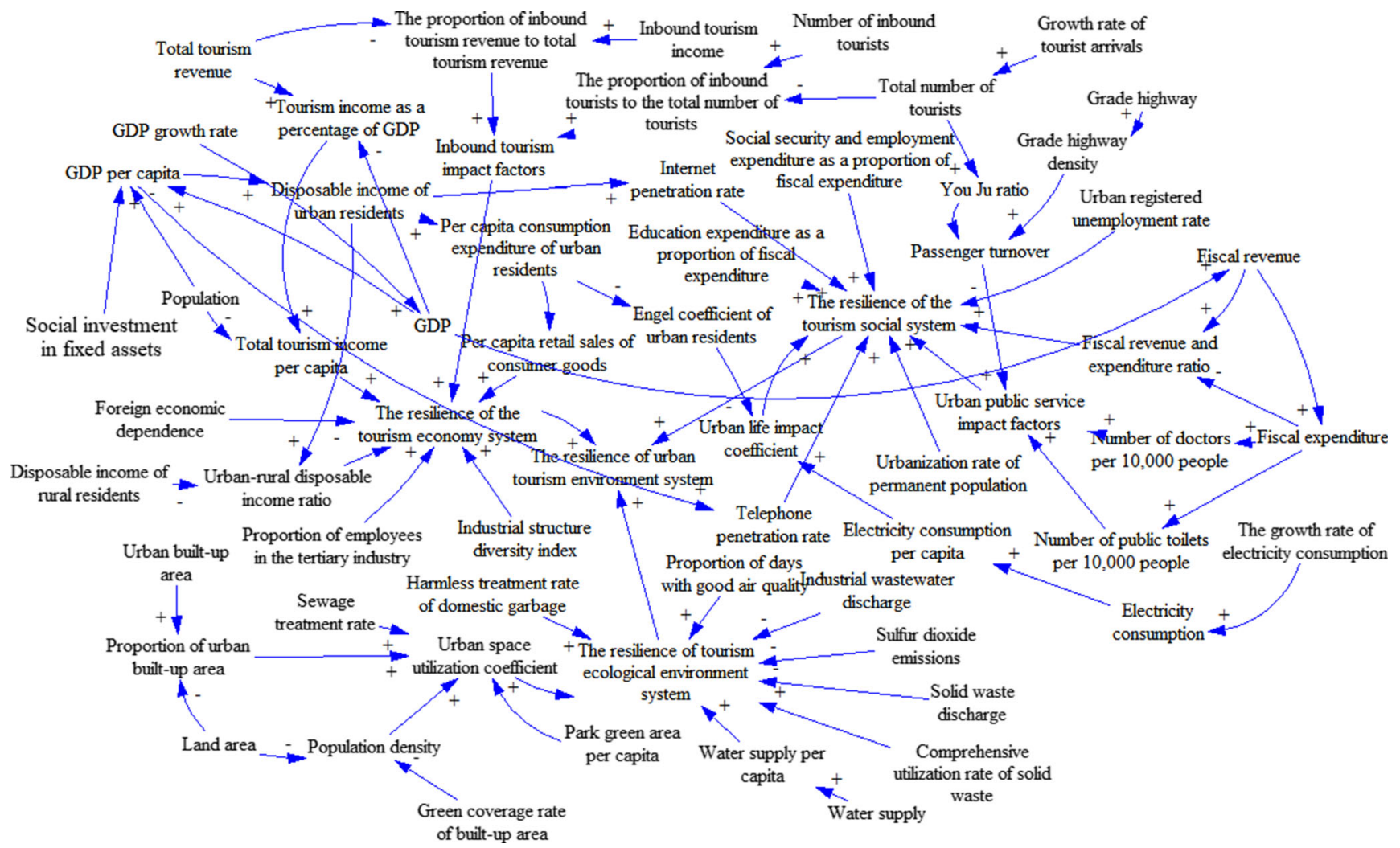

Fig. 3 Causality diagrams of the resilience variables of an UTES 


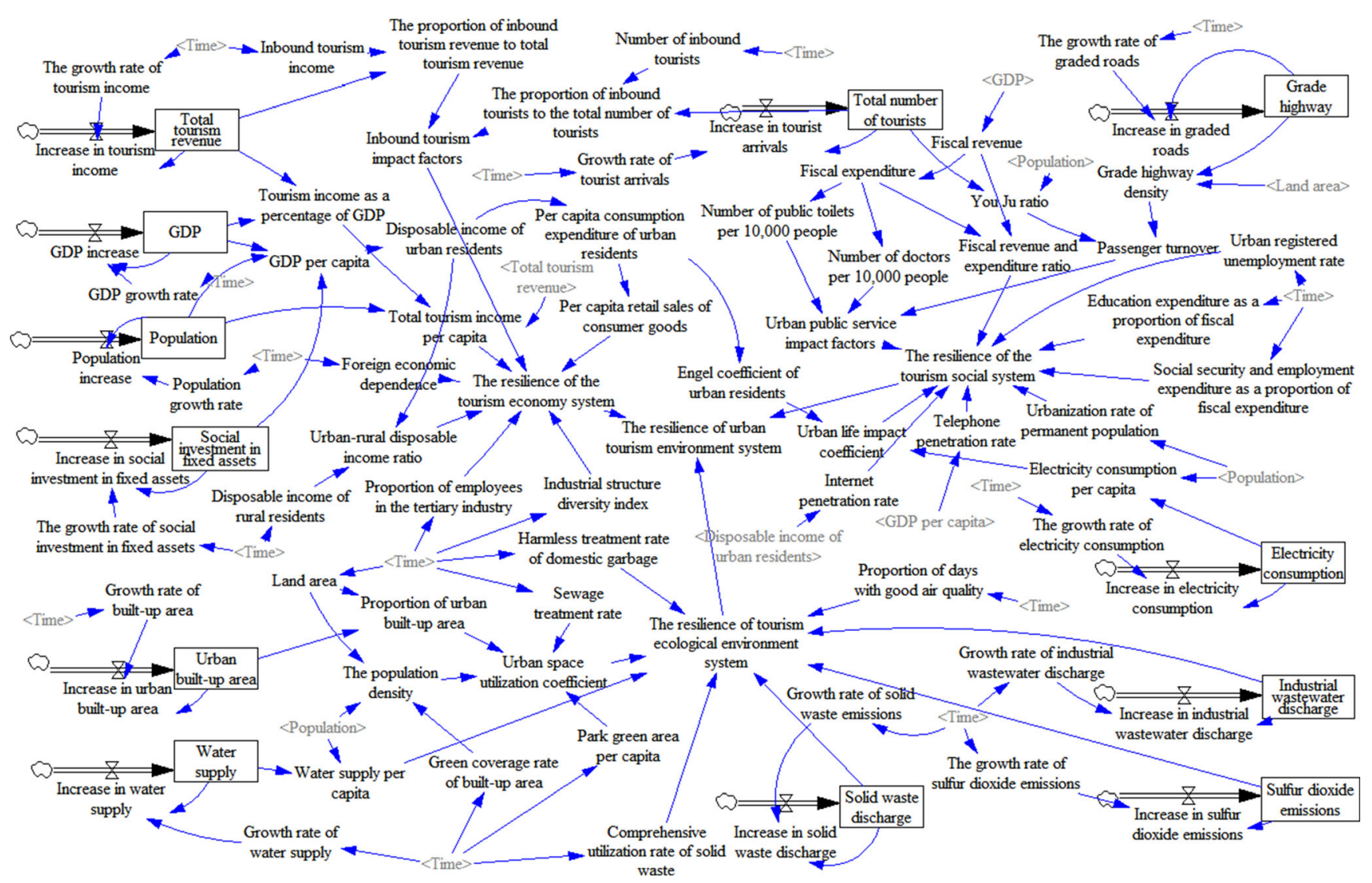

Fig. 4 Relationship between the stock and flow of resilience variables in an UTES

destination tourism environment, and the resilience of the tourism ecological environment system is key to the development of destination tourism resilience.

\section{Measurement of resilience in a tourism environment system}

To construct indicators for UTES resilience, the entropy method (Kim et al. 2019) is used, assessing the weights of the indicators given in Table 1. First, the indicators are normalized to obtain dimensionless standard value $R_{i j}$ of the urban tourism environmental resilience indicator.

The proportion of the $j$ item index in the $i-t h$ year:

$P_{i j}=R_{i j} / \sum_{i=1}^{m} R_{i j}$

Information entropy of the $j$ item index:

$E_{j}=-K \sum \ln P_{i j}, K=\frac{1}{\ln m}\left(0 \leq E_{j} \leq 1\right)$

Information redundancy of the $j$ item indicator:

$M_{j}=1-E_{j}$
The weight of the $j$ item indicator:

$W_{j}=M_{j} / \sum_{j=1}^{n} M_{j}$

Evaluation of individual indicators:

$Y_{i j}=W_{j} x_{i j}$

Comprehensive evaluation of resilience of urban tourism environment system in the $i-$ th year:

$x_{j}=\sum_{j=1}^{n} Y_{i j}$

The TOPSIS method is used to find the optimal and worst solutions in a decision-making scheme taking a cosine method, calculating the Euclidean distance between each evaluation unit and the optimal and worst solutions, calculating the relative proximity of each evaluation unit to the optimal solution, and evaluating the pros and cons of each decision plan based on the results of this procedure. The reciprocal method is then used to convert all indicators into high-quality indicators. The calculation goes as follows:

$\overline{X_{i j}}=\left\{\begin{array}{l}x_{i j} \\ 1 / x_{i j} \\ M /\left[M+\left|x_{i j}-M\right|\right]\end{array}\right.$ 
The corresponding matrix is established. The calculation method is as follows:

$$
z_{i j}=\left\{\begin{array}{l}
\frac{\overline{X_{i j}}}{\sqrt{\sum_{i=1}^{m}\left(\overline{X_{i j}}\right)^{2}}} \\
\frac{x_{i j}}{\sqrt{\sum_{i=1}^{m}\left(x_{i j}\right)^{2}}}
\end{array}\right.
$$

The normalized matrix is denoted as Z:

$$
Z=\left[\begin{array}{cccc}
z_{11} & z_{12} & \ldots & z_{1 n} \\
z_{21} & z_{22} & \ldots & z_{2 n} \\
\ldots & \ldots & \ldots & \ldots \\
z_{m 1} & z_{m 2} & \ldots & z_{m n}
\end{array}\right]
$$

The optimal solution $Z^{+}$consists of the maximum value in each column of Z:

$Z^{+}=\left(\max z_{i 1}, \max z_{i 2}, \ldots, \max z_{i n}\right)$

The worst solution $Z$ consists of the smallest value in each column of Z:

$Z^{-}=\left(\min z_{i 1}, \min z_{i 2}, \ldots, \min z_{i n}\right)$

The distance $d^{+}$and $d$ between each evaluation unit and $Z^{+}$ and $Z$ are calculated:

$$
\begin{aligned}
& d_{i}^{+}=\sqrt{\sum_{j=1}^{n} \omega_{j}\left(\max z_{i j}-z_{i j}\right)^{2}} \\
& d_{i}^{-}=\sqrt{\sum_{j=1}^{n} \omega_{j}\left(\min z_{i j}-z_{i j}\right)^{2}}
\end{aligned}
$$

The proximity $c_{i}$ of each evaluation unit to the optimal solution is calculated. The closer that $c_{i}$ is to 1 , the better the evaluation unit:

$c_{i}=\frac{d_{i}^{-}}{d_{i}^{+}+d_{i}^{-}} 0 \leq c_{i} \leq 1$

Finally, the ranking results of each evaluation unit are given, in relation to the size of $c_{i}$.

In the TOPSIS method, to calculate the evaluation unit for the positive ideal solution and the negative ideal solution, the weighting $\omega_{j}$ is subjectively assigned. To overcome the deviation caused by the subjective factors, this paper combines the entropy weight method and the TOPSIS method, using the entropy weight method to determine the weighting. The resulting evaluation is more objective.

$d_{i}^{+}=\sqrt{\sum_{j=1}^{n} \omega_{j}\left(\max z_{i j}-z_{i j}\right)^{2}}$ $d_{i}^{-}=\sqrt{\sum_{j=1}^{n} \omega_{j}\left(\min z_{i j}-z_{i j}\right)^{2}}$

In Formulas (15) and (16), $\omega_{j}$ is the weight value calculated by the entropy weight method, taking the place of the subjectively determined weight given in Formulas (11) and (12).

\section{Analysis on the temporal and spatial evolution track of the resilience center of regional UTES}

The analysis of the direction of movement and the change trajectory of the center of gravity allow the characteristics of the overall spatial distribution of the resilience of the regional UTES to be revealed, the coordinates of the cities in the region to be set, and the distribution equilibrium and the deviation of the center of gravity of the tourism environment system within the region to be measured. Using the standard deviation ellipse method, the basic parameters of the center of the ellipse, its major axis, minor axis, and azimuth angle are used to construct the spatial distribution ellipse. Analyzing the overall characteristics of the spatial distribution of the resilience of the regional UTES leads to a demonstration of the evolution of the spatial pattern of the resilience of the UTES, and the changes in spatial centrality, spatial distribution, spatial density, spatial orientation, and similarity of spatial shapes are analyzed.

To calculate the average center:

$\bar{X}=\frac{\sum_{i=1}^{m} w_{i} x_{i}}{\sum_{i=1}^{m} w_{i}} \bar{Y}=\frac{\sum_{i=1}^{m} w_{i} y_{i}}{\sum_{i=1}^{m} w_{i}}$

To obtain the SDE:

$X_{S D E}=\sqrt{\frac{\sum_{i=1}^{m} w_{i}^{2}\left(\widetilde{x}_{i} \cos \alpha-\widetilde{y}_{i} \sin \alpha\right)^{2}}{\sum_{i=1}^{m} w_{i}^{2}}}$

$Y_{S D E}=\sqrt{\sum_{i=1}^{m} w_{i}^{2}\left(\frac{\widetilde{\left.\widetilde{x}_{i} \sin \alpha-y \widetilde{\cos } \alpha\right)^{2}}}{\sum_{i=1}^{m} w_{i}^{2}}\right.}$

To measure the direction angle:

$$
\begin{gathered}
M=\sum_{i=1}^{m} w_{i}^{2} \widetilde{x_{i}^{2}}-\sum_{i=1}^{m} w_{i}^{2} \widetilde{y_{i}^{2}} \\
N=\sqrt{\left(\sum_{i=1}^{m} w_{i}^{2} \widetilde{x_{i}^{2}}-\sum_{i=1}^{m} w_{i}^{2} \widetilde{y_{i}^{2}}\right)^{2}+4 \sum_{i=1}^{m} w_{i}^{2} \widetilde{x_{i}^{2}} \widetilde{y_{i}^{2}}} \\
\tan \alpha=\frac{M+N}{Q} \\
Q=2 \sum_{i=1}^{m} w_{i}^{2} \widetilde{x_{i}} \widetilde{y_{i}}
\end{gathered}
$$


Table 2 Multi-scenarios setting of simulation parameters for the resilience of the tourism environment system

\begin{tabular}{|c|c|c|c|}
\hline Indicators & $\begin{array}{l}\text { Scenario } 1 \text { maintain } \\
\text { the status quo }\end{array}$ & $\begin{array}{l}\text { Scenario } 2 \\
\text { extensive growth }\end{array}$ & $\begin{array}{l}\text { Scenario } 3 \\
\text { sustainable growth }\end{array}$ \\
\hline Inbound tourism income & $\mathrm{O}$ & $\phi$ & $\odot$ \\
\hline Proportion of employees in the tertiary industry & $\mathrm{O}$ & $\phi$ & $\odot$ \\
\hline Harmless treatment rate of domestic garbage & $\mathrm{O}$ & $\odot$ & $\phi$ \\
\hline The speed of tourism revenue growth & $\mathrm{O}$ & $\phi$ & $\odot$ \\
\hline Number of inbound tourists & $\mathrm{O}$ & $\phi$ & $\odot$ \\
\hline Sewage treatment rate & $\mathrm{O}$ & $\odot$ & $\phi$ \\
\hline Solid waste discharge growth rate & $\mathrm{O}$ & $\phi$ & $\odot$ \\
\hline Park green area per capita & $\mathrm{O}$ & $\odot$ & $\phi$ \\
\hline Sulfur dioxide emissions growth rate & $\mathrm{O}$ & $\phi$ & $\odot$ \\
\hline GDP growth rate & $\mathrm{O}$ & $\phi$ & $\odot$ \\
\hline Population growth rate & $\mathrm{O}$ & $\phi$ & $\odot$ \\
\hline Urban registered unemployment rate & $\mathrm{O}$ & $\odot$ & $\odot$ \\
\hline Social security and employment expenditure as a proportion of fiscal expenditure & $\mathrm{O}$ & $\odot$ & $\phi$ \\
\hline Education expenditure as a proportion of fiscal expenditure & $\mathrm{O}$ & $\odot$ & $\phi$ \\
\hline Green coverage rate of built-up area & $\mathrm{O}$ & $\odot$ & $\phi$ \\
\hline Growth rate of tourist arrivals & $\mathrm{O}$ & $\phi$ & $\odot$ \\
\hline Grade highway growth rate & $\mathrm{O}$ & $\phi$ & $\odot$ \\
\hline Disposable income of rural residents & $\mathrm{O}$ & $\phi$ & $\phi$ \\
\hline Industrial structure diversity index & $\mathrm{O}$ & $\odot$ & $\phi$ \\
\hline Power consumption growth rate & $\mathrm{O}$ & $\phi$ & $\odot$ \\
\hline Foreign economic dependence & $\mathrm{O}$ & $\phi$ & $\odot$ \\
\hline Growth rate of social investment in fixed assets & $\mathrm{O}$ & $\phi$ & $\odot$ \\
\hline Land area & $\mathrm{O}$ & $\mathrm{O}$ & $\mathrm{O}$ \\
\hline Growth rate of built-up area & $\mathrm{O}$ & $\phi$ & $\odot$ \\
\hline Comprehensive utilization rate of solid waste & $\mathrm{O}$ & $\odot$ & $\phi$ \\
\hline Water supply growth rate & $\mathrm{O}$ & $\odot$ & $\odot$ \\
\hline Proportion of days with good air quality & $\mathrm{O}$ & $\odot$ & $\phi$ \\
\hline Industrial waste water discharge growth rate & $\mathrm{O}$ & $\odot$ & $\odot$ \\
\hline
\end{tabular}

Note: $\mathrm{O}$, remains unchanged; $\phi$, maximum value of the 11-year study period; $\odot$, minimum value of the 11-year study period; $\odot$, average value of the 11 year study period

In this formula, $\bar{X}$ and $\bar{Y}$ represent the abscissa and ordinate of the center of gravity of the region, respectively; $x_{i}$ and $y_{i}$ represent the coordinates of the $i$-th region; $m$ is the number of regions; and $\widetilde{x_{i}}$ and $\widetilde{y_{i}} \sim$ represent the coordinates of the region and the deviation of the center of gravity, respectively.

\section{Dynamic mechanism of resilience of UTES}

\section{Constructing a system dynamic model for UTES resilience}

In 1956, Professor J.W. Forrester of the Massachusetts Institute of Technology proposed a theory of system dynamics (SD), involving the analysis of information feedback systems using an interdisciplinary approach. Using Vensim software, adopting feedback characteristics that describe the mutual cause and effect of the internal components of a system, the root cause of a problem can be found from within a system's internal structure. We analyze the attributes of variables that indicate the resilience of an UTES, constructing a causal relationship diagram for its resilience (Fig. 3) and a stock flow diagram (Fig. 4), and test a SD model for it.

\section{Multi-scenario setting of resilience of an urban tourism environment system}

Drawing on relevant research results (Solomitckii et al. 2020; Ioannou et al. 2019), the resilience of the regional tourism environment system is investigated in multiple scenarios: maintaining the status quo (scenario 1), extensive growth (scenario 2), and sustainable growth (scenario 3 ). Table 2 shows the simulation parameters for the resilience of the system. 
$\frac{\bar{c}}{2}$

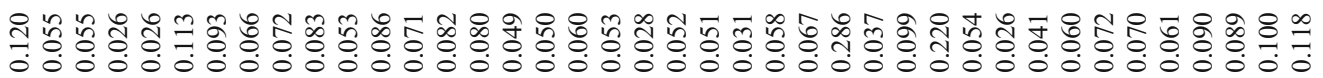

急

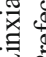

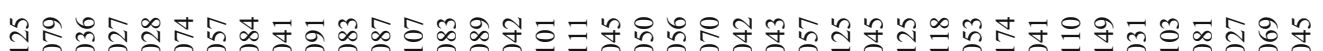

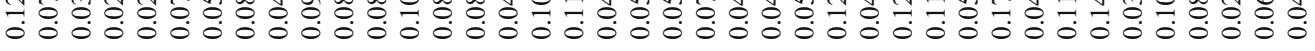

뜬

坣

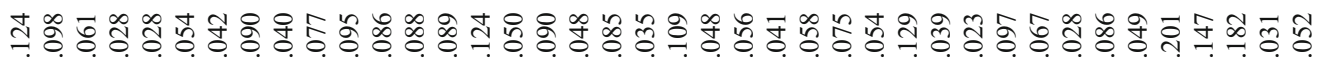

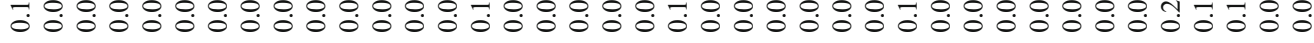

离

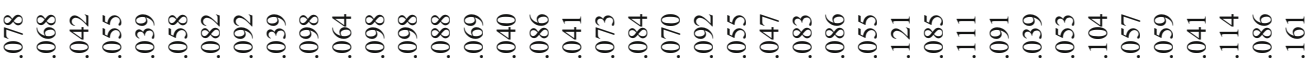

on

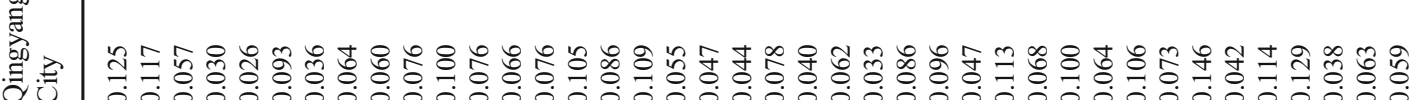
000000000000000000000000000000000000

ีㅡㄹ

丞

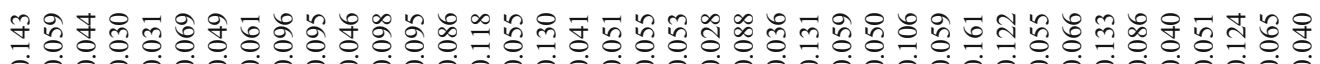

:

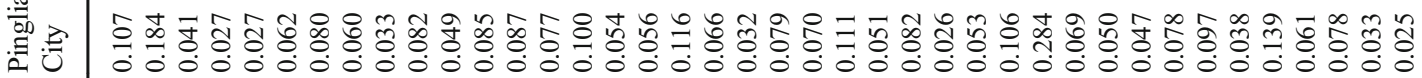

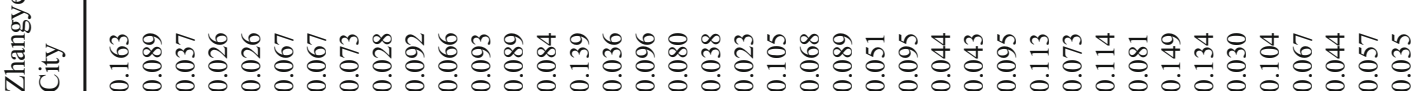

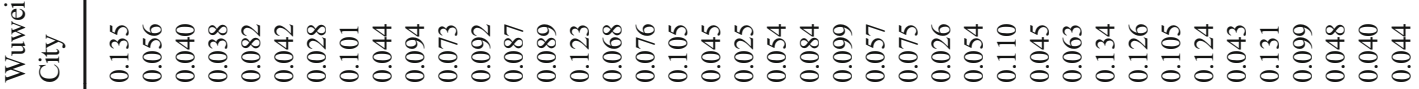

夆

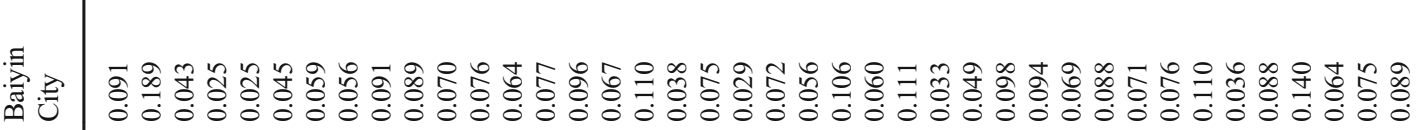

至色

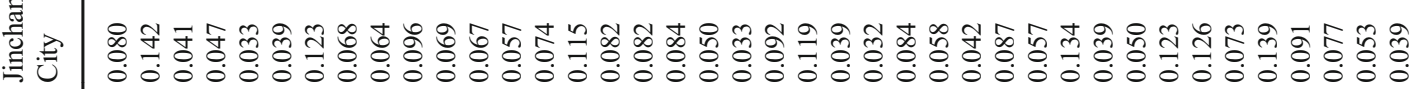

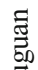

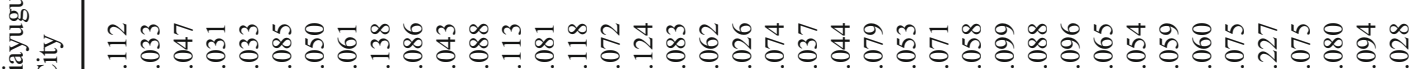

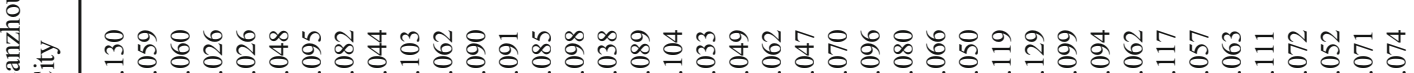

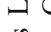

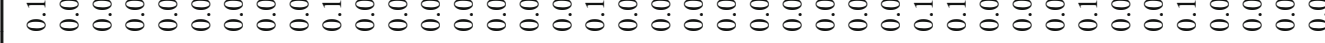

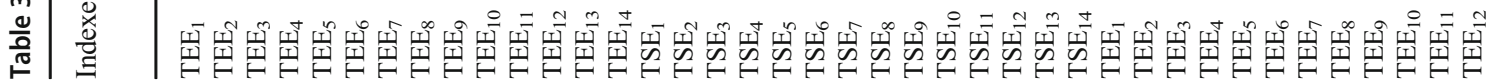


Table 4 Calculated values of resilience of UTES in Gansu Province

\begin{tabular}{llllllllllll}
\hline Cities & 2007 & 2008 & 2009 & 2010 & 2011 & 2012 & 2013 & 2014 & 2015 & 2016 & 2017 \\
\hline Lanzhou City & 0.232 & 0.258 & 0.335 & 0.326 & 0.345 & 0.364 & 0.398 & 0.469 & 0.501 & 0.647 & 0.689 \\
Jiayuguan City & 0.299 & 0.287 & 0.304 & 0.300 & 0.317 & 0.351 & 0.412 & 0.498 & 0.589 & 0.629 & 0.709 \\
Jinchang City & 0.286 & 0.475 & 0.170 & 0.172 & 0.244 & 0.229 & 0.269 & 0.332 & 0.417 & 0.465 & 0.462 \\
Baiyin City & 0.269 & 0.379 & 0.196 & 0.191 & 0.256 & 0.293 & 0.345 & 0.382 & 0.416 & 0.437 & 0.548 \\
Tianshui City & 0.310 & 0.217 & 0.264 & 0.350 & 0.219 & 0.277 & 0.287 & 0.343 & 0.430 & 0.495 & 0.652 \\
Wuwei City & 0.300 & 0.273 & 0.271 & 0.238 & 0.236 & 0.330 & 0.362 & 0.414 & 0.501 & 0.627 & 0.711 \\
Zhangye City & 0.279 & 0.285 & 0.358 & 0.344 & 0.239 & 0.288 & 0.382 & 0.442 & 0.444 & 0.561 & 0.655 \\
Pingliang City & 0.248 & 0.247 & 0.290 & 0.481 & 0.249 & 0.323 & 0.347 & 0.396 & 0.415 & 0.493 & 0.537 \\
Jiuquan City & 0.298 & 0.284 & 0.308 & 0.300 & 0.264 & 0.330 & 0.387 & 0.469 & 0.565 & 0.672 & 0.698 \\
Qingyang City & 0.318 & 0.319 & 0.350 & 0.440 & 0.377 & 0.326 & 0.364 & 0.443 & 0.478 & 0.541 & 0.539 \\
Dingxi City & 0.274 & 0.358 & 0.295 & 0.316 & 0.283 & 0.363 & 0.345 & 0.530 & 0.439 & 0.476 & 0.521 \\
Longnan City & 0.286 & 0.273 & 0.242 & 0.434 & 0.352 & 0.369 & 0.334 & 0.431 & 0.421 & 0.521 & 0.537 \\
Linxia Prefecture & 0.152 & 0.153 & 0.178 & 0.215 & 0.216 & 0.298 & 0.320 & 0.412 & 0.514 & 0.681 & 0.753 \\
Gannan Prefecture & 0.321 & 0.236 & 0.323 & 0.304 & 0.234 & 0.252 & 0.297 & 0.394 & 0.530 & 0.489 & 0.533 \\
\hline
\end{tabular}

\section{Data sources and positive analysis}

Gansu Province $\left(32^{\circ} 11^{\prime}-42^{\circ} 57^{\prime} \mathrm{N}, 92^{\circ} 13^{\prime}-108^{\circ} 46^{\prime}\right.$ E) is located deep inland in Northwest China. It has a land area of $425,800 \mathrm{~km}^{2}, 12$ prefecture-level cities, and 2 autonomous prefectures that are under the jurisdiction of the province. As of the end of 2019, the registered population of Gansu is $26,474,300$. There are 55 ethnic groups in the province. Various climate types are found in the province, with an average annual rainfall of about $300 \mathrm{~mm}$ and an average annual temperature of $0-15^{\circ} \mathrm{C}$. Most areas of the province have a dry climate, with arid and semi-arid areas accounting for $75 \%$ of the total area. Gansu Province is the birthplace of the Chinese nation and Chinese civilization, and it is located in the golden section and is a hub of the Silk Road. Here, Silk
Road culture intersects with Yellow River culture. Due to its unique natural resources, human heritage, and so on, it forms a regional ecological security barrier for the national political map and is part of a tourism image of the Symphonic Silk Road. In recent years, as Silk Road tourism has developed, the level of development of Gansu's tourism environment system has followed with it, its spatial pattern become more optimized day by day, and the resilience of the tourism environmental system has continued to advance. In 2018, 302.009 million domestic and foreign tourists visited Gansu Province, an increase of $26.34 \%$ over the previous year; domestic tourism revenue reached 205.83 billion Yuan, for an increase of $31.4 \%$. Research on the resilience of the UTES of Gansu Province has important theoretical and practical value for an improved integration of
Table 5 Standard deviation ellipse parameters of the resilience of the urban tourism economic environment subsystem

\begin{tabular}{llllllll}
\hline Years & $\begin{array}{l}\text { Shape } \\
\text { length }\end{array}$ & $\begin{array}{l}\text { Shape } \\
\text { area }\end{array}$ & $\begin{array}{l}\text { Center } \\
\text { X }\end{array}$ & $\begin{array}{l}\text { Center } \\
\text { Y }\end{array}$ & $\begin{array}{l}\text { Long semi- } \\
\text { axis }\end{array}$ & $\begin{array}{l}\text { Short semi- } \\
\text { axis }\end{array}$ & $\begin{array}{l}\text { Rotation } \\
\text { angle }\end{array}$ \\
\hline 2007 & 22.679 & 25.287 & 103.04 & 36.715 & 5.168 & 1.558 & 120.715 \\
2008 & 21.851 & 23.188 & 103.041 & 36.837 & 4.991 & 1.479 & 120.623 \\
2009 & 22.924 & 25.227 & 102.996 & 36.727 & 5.247 & 1.531 & 119.903 \\
2010 & 22.734 & 25.255 & 103.432 & 36.444 & 5.187 & 1.55 & 119.909 \\
2011 & 22.439 & 24.662 & 103.195 & 36.64 & 5.117 & 1.535 & 120.277 \\
2012 & 22.341 & 23.716 & 103.099 & 36.658 & 5.123 & 1.474 & 120.787 \\
2013 & 22.598 & 23.882 & 102.938 & 36.794 & 5.197 & 1.463 & 120.346 \\
2014 & 22.518 & 24.015 & 102.959 & 36.728 & 5.167 & 1.48 & 120.684 \\
2015 & 22.705 & 24.649 & 102.843 & 36.786 & 5.201 & 1.509 & 120.647 \\
2016 & 22.602 & 23.93 & 102.848 & 36.808 & 5.196 & 1.466 & 120.599 \\
2017 & 22.37 & 23.299 & 102.867 & 36.794 & 5.148 & 1.441 & 120.867 \\
\hline
\end{tabular}


Fig. 5 Standard deviation ellipse of resilience of UTES

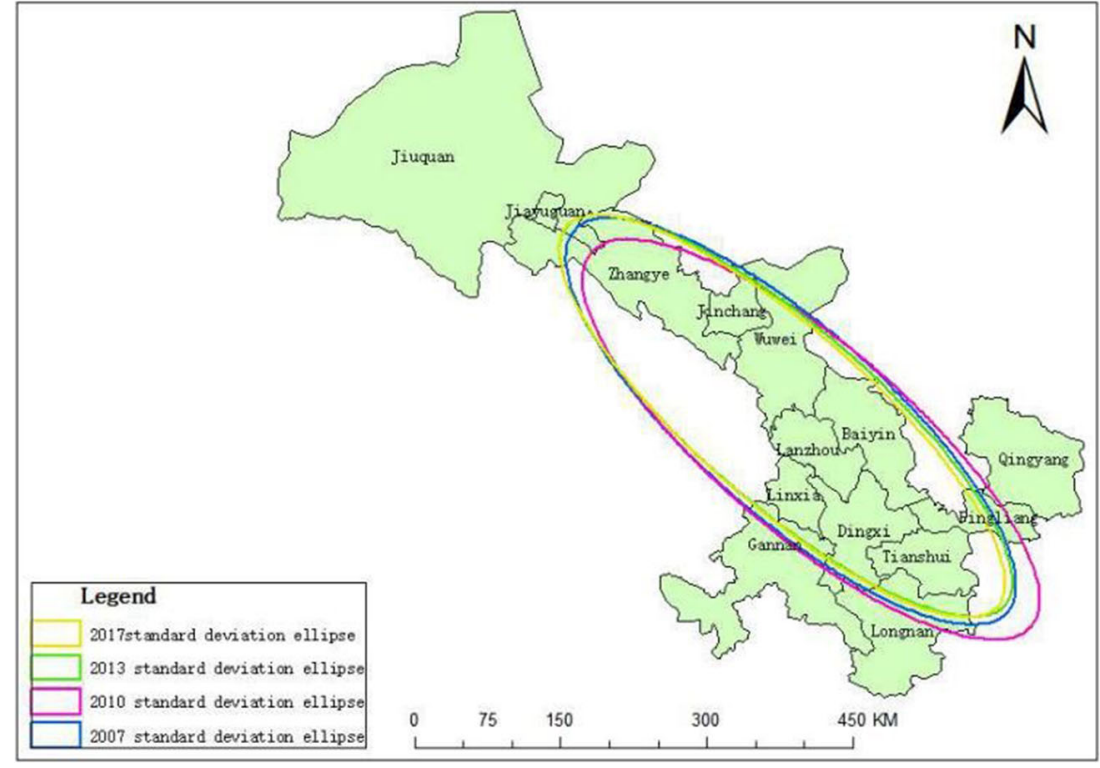

regional resources and promotion of tourism integration of tourism. Study on the resilience of the urban tourism environmental system of the Gansu section of the Silk Road will help support the great practice of tourism development in the Western part of the country. Gansu Province features a fragile ecological environment. The challenges of the expansion of urban spaces and population agglomerations have led to a contradiction between man and land to Gansu Province. At the same time, Lanzhou's low and peak tourism seasons are obvious. The combined demand of multiple entities in the peak season increases the pressure on the UTES.

Data on the resilience of the urban tourism environment system in Gansu Province are drawn from the following publications for 2007-2018: China Urban Statistical Yearbook, China Regional Economic Statistical Yearbook, China Urban

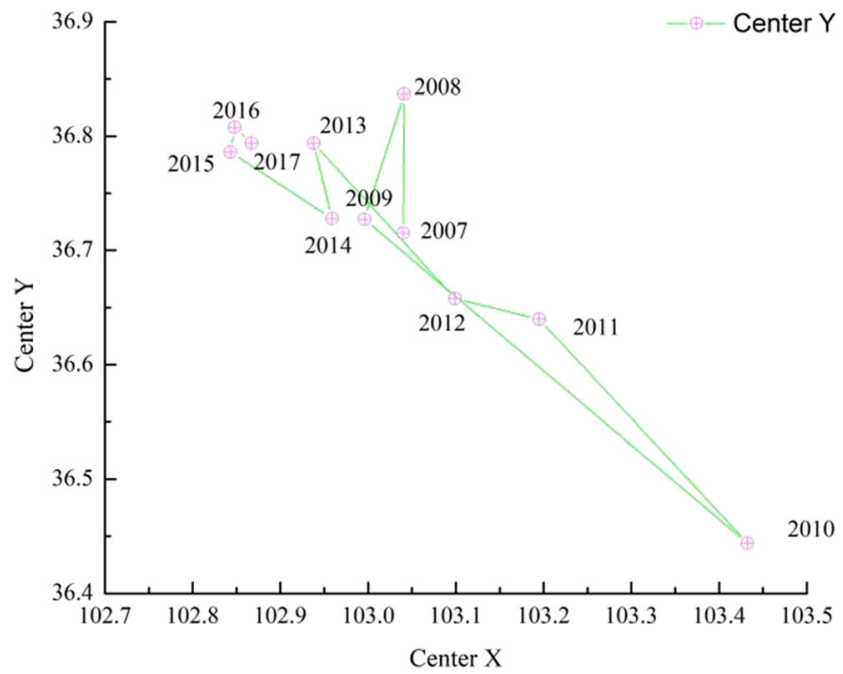

Fig. 6 Trajectory of the center of gravity of the resilience of the urban tourism environment system
Construction Statistical Yearbook, Gansu Development Statistical Yearbook, Gansu Yearbook, and Gansu City Yearbook, among others. The missing data are supplied by taking the means of adjacent data and interpolating them.

\section{Weighting of the evaluation indexes for resilience of the UTES in Gansu Province}

The statistical data on the resilience index of the tourism environment system in 14 cities of Gansu Province, using range standardization, are assessed using Formulas (1)-(6) to determine the weighting of the UTES resilience evaluation index, presented in Table 3.

\section{Evaluation of the resilience of the UTES in Gansu Province}

Using Formulas (7)-(16), the resilience of the tourism environmental system is calculated for 14 cities of Gansu Province from 2007 to 2017. These showed an upward trend in this time frame, and the development was relatively stable. During this period, resilience rose and fell alternately, exhibiting a certain volatility. It had a wave-like trend, cascading through rapid improvement, slow decline, and re-improvement. The resilience of Gansu's UTES is continuing to improve, but its overall resilience remains low. The development and degree of resilience of the system are quite different in different periods, as shown in Table 4.

The development of the resilience of the tourism environment system in cities at all levels in Gansu Province can largely be seen as lagging, stable, and improving. The development of the resilience can be divided into three periods: The period from 2007 to 2011 was the lagging stage in the development of the system. In 2011, resilience was still low. Although 
Table 6 Standard deviation ellipse parameters of the resilience of the urban tourism economic environment subsystem

\begin{tabular}{llllllll}
\hline Years & $\begin{array}{l}\text { Shape } \\
\text { length }\end{array}$ & $\begin{array}{l}\text { Shape } \\
\text { area }\end{array}$ & $\begin{array}{l}\text { Center } \\
\text { X }\end{array}$ & $\begin{array}{l}\text { Center } \\
\text { Y }\end{array}$ & $\begin{array}{l}\text { Long semi- } \\
\text { axis }\end{array}$ & $\begin{array}{l}\text { Short semi- } \\
\text { axis }\end{array}$ & $\begin{array}{l}\text { Rotation } \\
\text { angle }\end{array}$ \\
\hline 2007 & 21.365 & 22.269 & 103.269 & 36.7 & 4.876 & 1.454 & 120.692 \\
2008 & 20.361 & 20.827 & 103.279 & 36.707 & 4.62 & 1.435 & 122.071 \\
2009 & 22.374 & 25.023 & 102.969 & 36.593 & 5.082 & 1.568 & 121.426 \\
2010 & 23.046 & 25.744 & 103.54 & 36.317 & 5.266 & 1.557 & 119.614 \\
2011 & 23.104 & 25.099 & 103.015 & 36.856 & 5.308 & 1.506 & 118.493 \\
2012 & 22.917 & 24.322 & 102.928 & 36.745 & 5.278 & 1.467 & 120.532 \\
2013 & 23.15 & 24.441 & 102.811 & 36.851 & 5.346 & 1.456 & 120.103 \\
2014 & 22.904 & 24.26 & 102.885 & 36.755 & 5.277 & 1.464 & 120.766 \\
2015 & 22.72 & 25.24 & 102.77 & 36.78 & 5.183 & 1.55 & 120.919 \\
2016 & 22.834 & 24.233 & 102.725 & 36.865 & 5.256 & 1.468 & 120.679 \\
2017 & 22.722 & 23.406 & 102.685 & 36.915 & 5.252 & 1.419 & 120.842 \\
\hline
\end{tabular}

Gansu Province had achieved major development of its tourism economy through attracting tourists, taking advantage of its tourism resources, and leveraging the policy dividends, there was a decline in the quality of urban tourism ecological environment, so it was not obvious that the urban tourism environmental system resilience had improved. From 2011 to 2013, resilience developed in a stable pattern with relatively small fluctuations. From 2013 to 2017, it rapidly improved. Due to the increased resource inputs and the improved infrastructure, the tourism economy experienced rapid development. Efforts to protect the ecological environment of urban tourism were put forward, resilience showed rapid development, and the ecological environment had continuous improvement.

\section{Analysis of the trajectory of temporal and spatial evolution of the center of gravity of resilience of the tourism environment system of 14 cities of Gansu Province}

Using Formulas (17)-(20), the position of the center of gravity of the resilience of the UTES in Gansu Province is calculated, and the change trend of the standard deviation ellipse and the track of the evolution of the center of gravity are drawn using ArcGIS software. From 2007 to 2017, the scope of the resilience of the UTES was reduced. The standard deviation of the resilience of the UTES on the short semi-axis of the ellipse fell from 1.558 in 2007 to 1.441 in 2017 , a decrease of 0.117 ; at the same time, the standard deviation of the semi-major axis fell from 5.168 in 2007 to 5.148 in 2017 , a decrease of 0.02 .
Fig. 7 Standard deviation ellipse of resilience of urban tourism economic environment subsystem

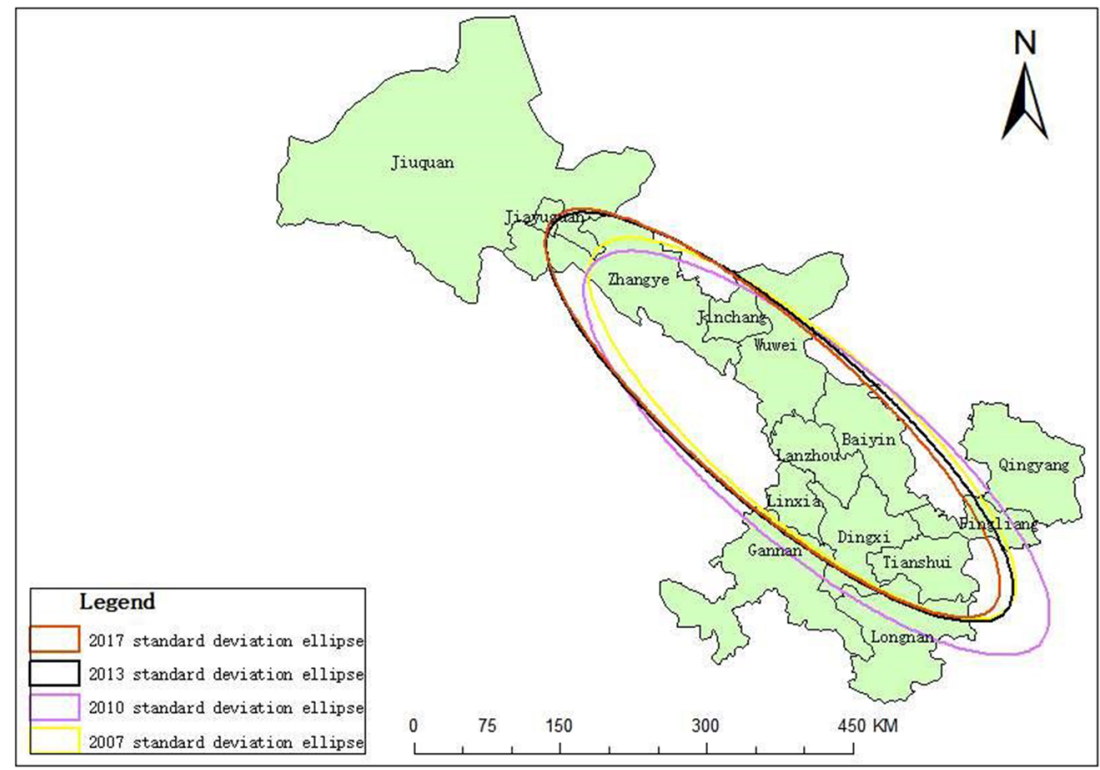




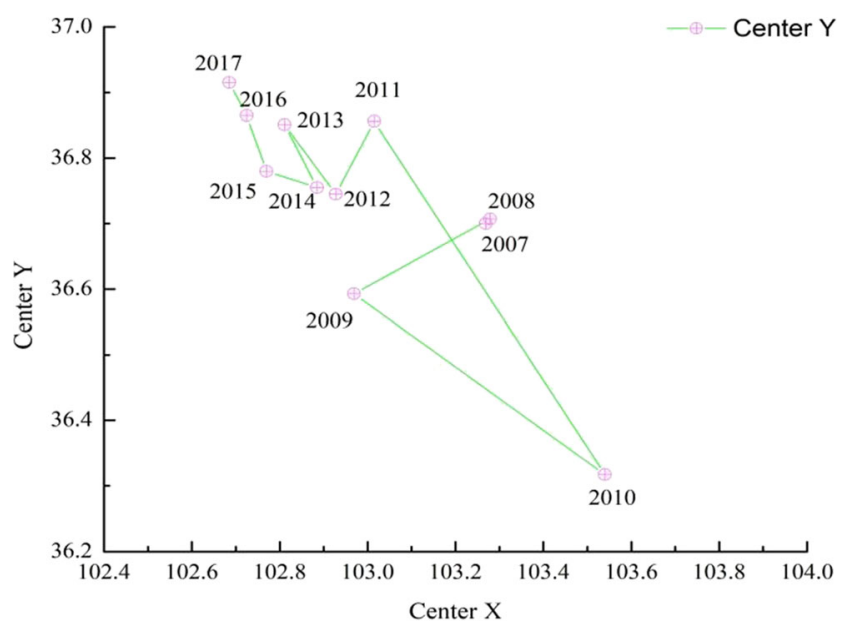

Fig. 8 Trajectory of the center of gravity of the resilience of the urban tourism economic environment subsystem

The orientation of the resilience of the UTES rotates clockwise and gradually deviates from true north. The azimuth of the resilience of the UTES in Gansu Province deviates from true north in a clockwise direction. The azimuth angle was $120.715^{\circ}$ in 2007 and reached $120.867^{\circ}$ in 2017 , as shown in Table 5 and Fig. 5. From 2007 to 2017, the central value for $\mathrm{x}$ was 103.04 in 2007 and 102.867 in 2017, and the central value for $y$ was 36.715 in 2007 and 36.794 in 2017. The center of gravity of the resilience of the UTES appeared to move to the northwest of Gansu Province, to Lanzhou, as shown in Fig. 6.

The resilience of the urban tourism economic environment subsystem first expanded and then decreased, showing an overall spatial expansion. The standard deviation of the short semi-axis of the ellipse of the resilience of the urban tourism economic environment subsystem decreased from 1.454 in 2007 to 1.419 in 2017, for a decrease of 0.035 . The standard deviation of the long semi-axis grew from 4.876 in 2007 to 5.252 in 2017, an increase of 0.376 . The orientation of the resilience of the urban tourism economic environment subsystem in Gansu Province fluctuated. It deviated from the true north in a clockwise direction, moving from $120.692^{\circ}$ in 2007 to $120.842^{\circ}$ in 2017 , as shown in Table 6 and Fig. 7. Analysis of the time and space process of the resilience of the urban tourism economic environment subsystem of Gansu Province from 2007 to 2017 shows that the center of gravity of the resilience of the urban tourism economic environment subsystem of Gansu Province showed a tendency to move to the northwest of Gansu Province. The central x value in 2007 was 103.269 , reaching 102.685 in 2017 ; the central y value was 36.7 in 2007, the minimum, and it reached 36.915 in 2017 , the maximum. The center of gravity of the resilience of the urban tourism economic environment subsystem moved to the northwest of Gansu Province, slowly shifting from Lanzhou to Wuwei and back to Lanzhou, as shown in Fig. 8.

The spread of the resilience of urban tourism social environment subsystem was reduced. The standard deviation for the value of the short semi-axis of the ellipse for the resilience of the urban tourism social environment subsystem decreased from 1.518 in 2007 to 1.499 in 2017, a decrease of 0.019 . The standard deviation for the long semi-axis decreased from 5.333 in 2007 to 5.022 in 2017 , a decrease of 0.311 . The direction of the resilience of the urban tourism social environment subsystem rotated clockwise and gradually deviated from true north. The orientation of the resilience of the urban tourism social environment subsystem in Gansu Province fluctuated to a certain extent, deviating from true north in a clockwise direction. The azimuth of resilience of the urban tourism social environment subsystem was $121.302^{\circ}$ in 2007, and it reached $120.746^{\circ}$ in 2017 , as shown in Table 7 and Fig. 9. From 2007 to 2017, the center of gravity of the resilience of the urban tourism social environment subsystem of Gansu Province moved to the southeast. The central $\mathrm{x}$ value was 102.916 in 2007 and 103.105 in 2007. The central y value was 36.855 in 2007 and 36.62 in 2017. The center of gravity mainly moved toward Lanzhou, as shown in Fig. 10.
Table 7 Standard deviation ellipse parameters for the resilience of urban tourism social environment subsystem

\begin{tabular}{llllllll}
\hline Years & $\begin{array}{l}\text { Shape } \\
\text { length }\end{array}$ & $\begin{array}{l}\text { Shape } \\
\text { area }\end{array}$ & $\begin{array}{l}\text { Center } \\
\text { X }\end{array}$ & $\begin{array}{l}\text { Center } \\
\text { Y }\end{array}$ & $\begin{array}{l}\text { Long semi- } \\
\text { axis }\end{array}$ & $\begin{array}{l}\text { Short semi- } \\
\text { axis }\end{array}$ & $\begin{array}{l}\text { Rotation } \\
\text { angle }\end{array}$ \\
\hline 2007 & 23.225 & 25.431 & 102.916 & 36.855 & 5.333 & 1.518 & 121.302 \\
2008 & 22.876 & 25.417 & 102.975 & 36.822 & 5.225 & 1.549 & 121.106 \\
2009 & 22.626 & 25.09 & 103.167 & 36.589 & 5.159 & 1.548 & 120.913 \\
2010 & 22.324 & 25.313 & 103.243 & 36.563 & 5.054 & 1.595 & 121.481 \\
2011 & 21.52 & 23.094 & 103.249 & 36.599 & 4.89 & 1.504 & 121.964 \\
2012 & 21.703 & 22.973 & 103.162 & 36.657 & 4.953 & 1.477 & 121.267 \\
2013 & 21.926 & 23.000 & 103.000 & 36.793 & 5.022 & 1.458 & 120.829 \\
2014 & 22.117 & 23.391 & 103.005 & 36.748 & 5.066 & 1.47 & 121.009 \\
2015 & 22.26 & 23.518 & 102.91 & 36.853 & 5.106 & 1.467 & 120.607 \\
2016 & 22.372 & 23.929 & 103.037 & 36.734 & 5.125 & 1.487 & 120.372 \\
2017 & 22.009 & 23.647 & 103.105 & 36.62 & 5.022 & 1.499 & 120.746 \\
\hline
\end{tabular}


Fig. 9 Standard deviation ellipse for the resilience of urban tourism social environment subsystem

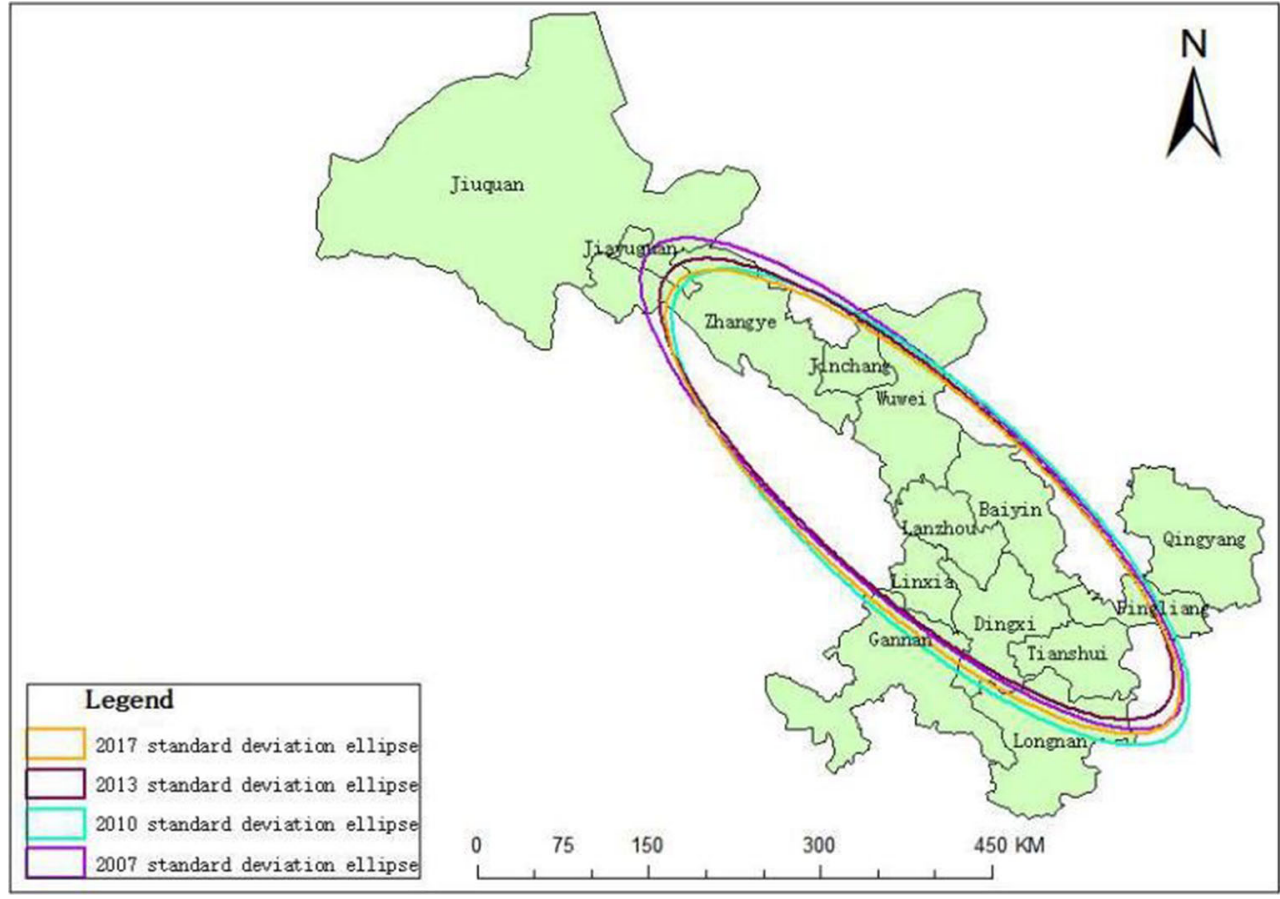

The scope of the spread of the resilience of the urban tourism ecological environment subsystem was significantly reduced. From 2007 to 2017, the standard deviation of the resilience of the urban tourism ecological environment subsystem fell from 1.591 in 2007 to 1.383 in 2017, a difference of 0.208 . The standard deviation of the long semi-axis fell from 5.527 in 2007 to 4.925 in 2017 , a difference of 0.602 . The orientation of the resilience of the urban tourism ecological environment subsystem in Gansu Province fluctuated in a clockwise direction, away from the true north. The azimuth angle of the resilience of the subsystem was $119.467^{\circ}$ in 2007 and reached $121.554^{\circ}$ in 2017 , as shown in Table 8 and Fig. 11. The temporal and spatial development of the resilience of

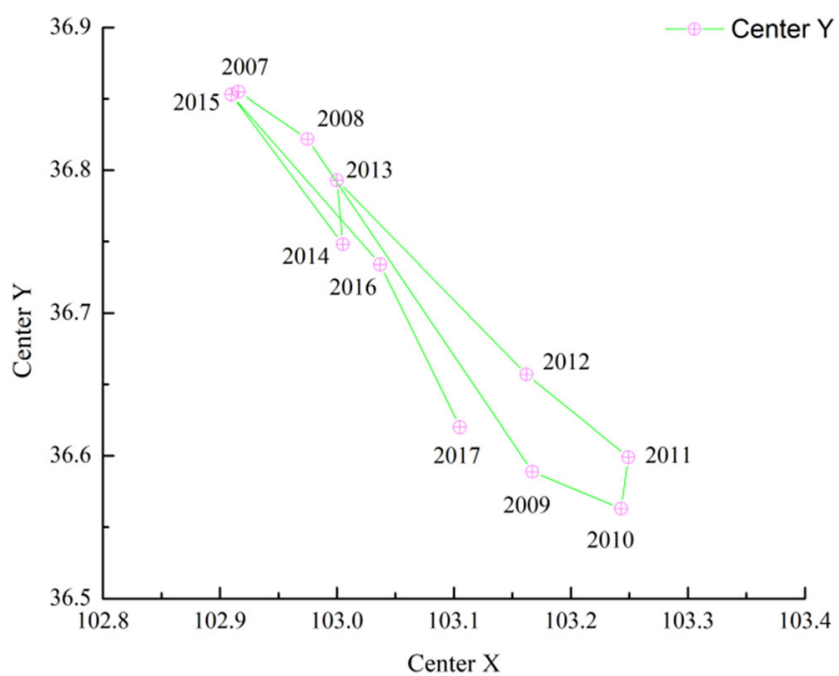

Fig. 10 Trajectory of the center of gravity for the resilience of the urban tourism social environment subsystem urban tourism ecological environment subsystem is analyzed in Gansu Province from 2007 to 2017 . The center of gravity of the resilience of the urban tourism ecological environment system in Gansu Province showed a tendency to move to the northwest of Gansu Province. The central $x$ value was 103.046 in 2007 and 102.862 in 2007 , and the central y value was 36.633 in 2007 and 36.836 in 2017 . The center of gravity of the resilience of the urban tourism ecological environment subsystem moved to the northwest of Gansu Province, and the center of gravity mainly moved toward Lanzhou, as shown in Fig. 12.

\section{SD simulation of resilience of tourism environment system in 14 cities of Gansu Province}

\section{Simulation of the current state of resilience of the tourism environmental systems in 14 cities of Gansu Province}

Vensim PLE software is used to simulate total tourism revenue for the key variables of the UTES and its resilience in Gansu Province to establish trends in evolution trend and the characteristics of the resilience of the system in Gansu Province. From 2007 to 2030, the resilience of the tourism environment system in most Gansu Province cities fluctuated, and it increased as a whole, following the development of the urban economy. Total tourism revenues increased in most cities. Governmental revenues increased investment about education and social security increased, and the urban ecological environment improved. The quality of urban development improved, and the resilience of the urban tourism environment 
Table 8 Standard deviation ellipse parameters of the resilience of the urban tourism ecological environment subsystem

\begin{tabular}{llllllll}
\hline Years & $\begin{array}{l}\text { Shape } \\
\text { length }\end{array}$ & $\begin{array}{l}\text { Shape } \\
\text { area }\end{array}$ & $\begin{array}{l}\text { Center } \\
\text { X }\end{array}$ & $\begin{array}{l}\text { Center } \\
\text { Y }\end{array}$ & $\begin{array}{l}\text { Long semi- } \\
\text { axis }\end{array}$ & $\begin{array}{l}\text { Short semi- } \\
\text { axis }\end{array}$ & $\begin{array}{l}\text { Rotation } \\
\text { angle }\end{array}$ \\
\hline 2007 & 24.103 & 27.62 & 103.046 & 36.633 & 5.527 & 1.591 & 119.467 \\
2008 & 24.076 & 26.066 & 102.873 & 36.908 & 5.572 & 1.49 & 118.585 \\
2009 & 23.842 & 24.791 & 103.051 & 36.858 & 5.543 & 1.424 & 117.673 \\
2010 & 23.031 & 25.204 & 103.282 & 36.613 & 5.281 & 1.519 & 118.954 \\
2011 & 22.143 & 24.183 & 103.327 & 36.379 & 5.043 & 1.527 & 121.088 \\
2012 & 21.815 & 22.86 & 103.318 & 36.541 & 4.993 & 1.458 & 120.615 \\
2013 & 22.233 & 23.935 & 103.117 & 36.681 & 5.081 & 1.5 & 120.366 \\
2014 & 22.066 & 24.566 & 103.053 & 36.637 & 5.002 & 1.563 & 120.458 \\
2015 & 23.278 & 24.478 & 102.844 & 36.755 & 5.383 & 1.448 & 120.489 \\
2016 & 21.799 & 22.211 & 102.834 & 36.843 & 5.013 & 1.411 & 121.321 \\
2017 & 21.408 & 21.387 & 102.862 & 36.836 & 4.925 & 1.383 & 121.554 \\
\hline
\end{tabular}

system increased. However, resilience in some cities, after first rising, fell and rose again, largely because the development of urban tourism economy is still relatively extensive, and the tourism ecological environment faced increased pressure. Among these developments, the resilience of the urban tourism environmental system of Lanzhou was greatly improved. The simulation value for the resilience of the tourism environmental system in 2030 was 0.92 . In recent years, Lanzhou increased its investment in education to provide important guarantees for the development of the tourism economy, and the greening level of its urban parks continuously improved. The ratio of days with good air quality was stable, and the treatment of waste water and waste gas was continuously improved. Not only has Lanzhou attracted more leisure and sightseeing tourists, it has also promoted the development of its urban tourism economy and enhanced the resilience of its urban tourism environment system. Due to the continuous improvements to internet penetration and telephone penetration, the transmission of tourism information is now more convenient, which has increased the number of urban tourists. Improvements in urban infrastructure construction are promoting the development of urban tourism resources and the development of the tourism economy, further promoting the improvement of the resilience of the urban tourism environment system. The resilience of the system of the cities of Zhangye Longnan, Linxia Prefecture, and the city of Jiuquan was greatly improved, but the resilience of the urban tourism environment system of the city of Qingyang is expected to
Fig. 11 Standard deviation ellipse of the resilience of the urban tourism ecological environment subsystem

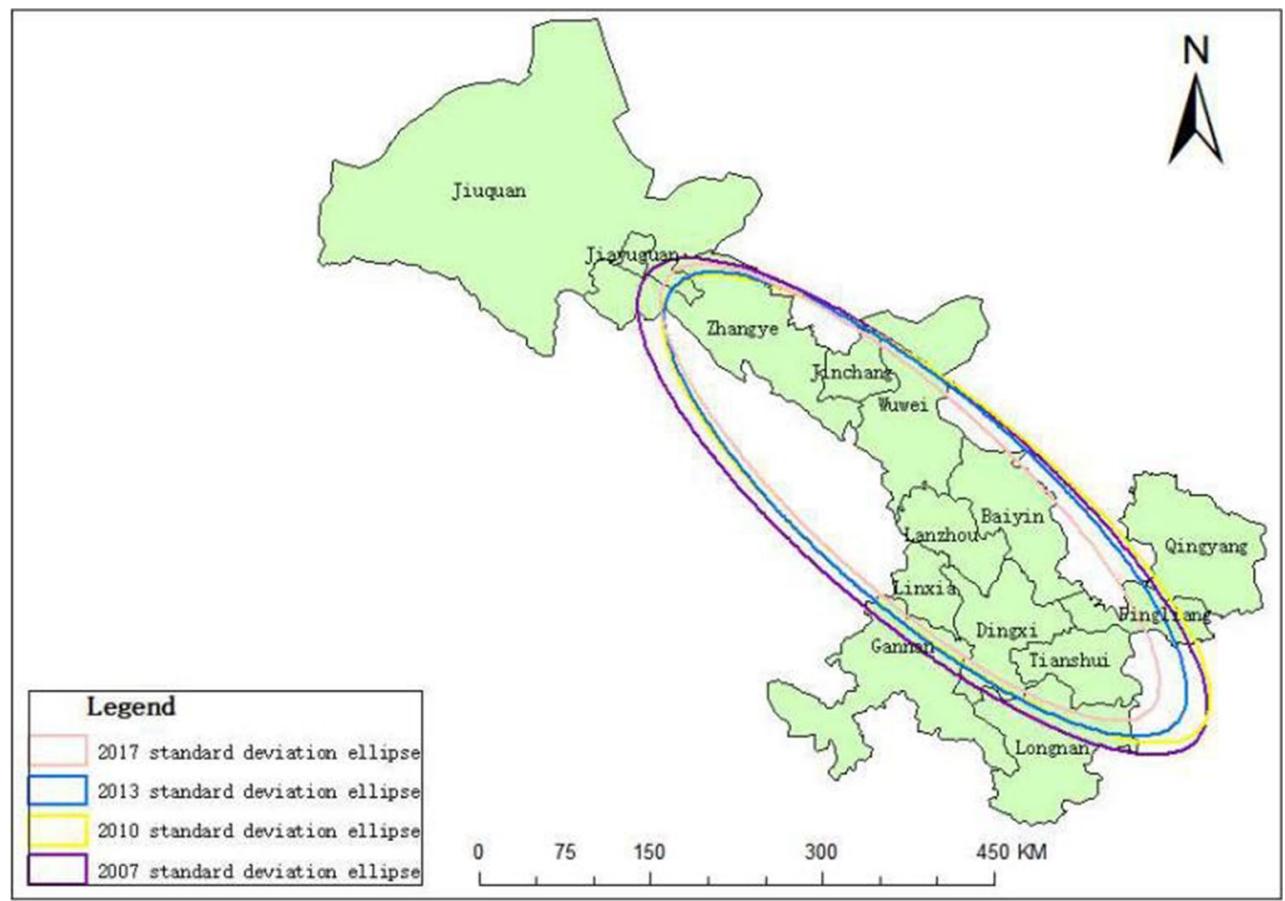




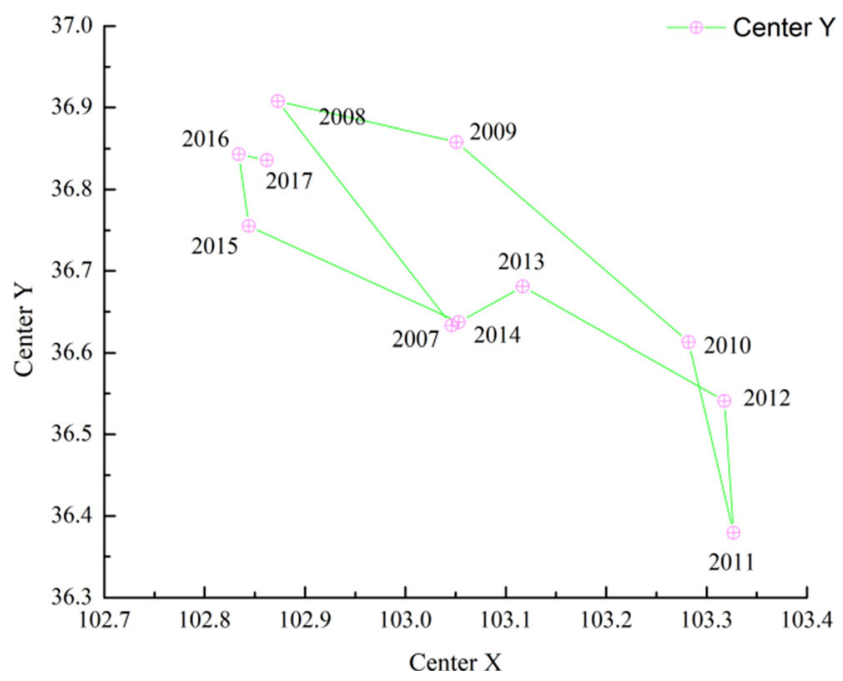

Fig. 12 Track of the center of gravity of the resilience of the urban tourism ecological environment subsystem

decline. The simulation value of the resilience of the UTES in 2030 is 0.45 . The decline in resilience of the UTES is mainly affected by the industrial structure; secondary industry accounts for a large proportion of GDP. Pollutant emissions have not been effectively controlled. The urban tourism economic development is relatively slow. Therefore, the resilience of the UTES shows more room for improvement. The simulation of the resilience of the UTES in Gansu Province from 2007 to 2030 showed that the evolution of the resilience of the system as a whole features a trend of increase. Further development of the urban tourism economy and the additional improvement of urban infrastructure are enhancing the resilience of the UTES to external disturbances and are supporting the sustainable development of most UTES, as shown in Fig. 13.

\section{Simulation of the resilience of tourism environment system in multiple scenarios in 14 cities of Gansu Province}

Using Vensim PLE software, a multi-scenario simulation of the resilience of the urban tourism environment system of Gansu Province is carried out. The trends and characteristics of the resilience of the system in three scenarios, namely, of maintaining the status quo, extensive growth, and sustainable growth, were simulated. From 2007 to 2017, the resilience of the tourism environment system of various cities of Gansu Province showed a fluctuating upward trend. From 2017 to 2030 , the growth of resilience slowed in scenario 3, but it increased significantly, and the declining resilience of some urban tourism environmental systems was eased. In particular, the resilience of the urban tourism environment system in the city of Baiyin improved relatively quickly from 2007 to 2030 , and with a simulated resilience value of 0.62 , higher than the resilience level in the extensive development of scenario 2 . In the short term, the resilience of the UTES for the city of
Dingxi was higher in scenario 2 than in scenario 1 , but over the long run, extensive development was shown to be unsustainable, and the resilience of the UTES was lower than maintaining in the status quo. The resilience of the UTES the city of Qingyang under the three scenarios first showed a rising trend and then a falling one, indicating that Qingyang still needed to increase expenditures on infrastructure construction, education, social security, and other goals, and fiscal expenditures needed to be appropriately expanded to ensure improved resilience of the UTES and to maintain the system's resilience to external shocks. However, the three scenario simulations of the resilience of the UTES in the city of Jiayuguan all show a downward trend, indicating that the development of the tourism economy necessarily increases the pressure on the ecological environment to a certain extent, resulting in a decline in environmental quality, which restricts the improvement of the resilience of the UTES. From 2007 to 2030, the resilience of the UTES in Gansu Province showed an overall upward trend of fluctuations in all three simulation scenarios. Scenario 2 showed faster development of tourism economy than scenario 3 and maintained a higher growth rate of tourism development. Over the short term, the resilience of the UTES was relatively high in scenario 2 , but over the long run, its resilience was still lower than in scenario 3. One-sided pursuit of economic development in the short term can increase the speed of the growth of the urban economy, but the longterm damage to the ecological environment and the associated tourism resources will be greater, which is not conducive to improving resilience in the UTES or the sustainable development of the urban tourism economy. In scenario 3, the speed of development of the resilience of the tourism economy was moderate, and more attention was paid to the quality of the development of the tourism economy. This improved the resilience level of the UTES and promoted the sustainable development of the UTES by eliminating the development model that features one-sided pursuit of extensive economic growth, as shown in Fig. 14.

\section{Conclusion}

As more and more theoretical research into the sustainable tourism city is being conducted, the resilience of UTES has become developed into a new approach to urban sustainable development and the mainstream direction of urban development worldwide. Resilience theory is providing new ideas for the study of tourism environmental systems, and it is becoming essential to identify sustainable development for regional tourism destinations. As tourism development continues to take place, the theory of resilience can help support the creation of a good tourism environment and experience for multiple subjects. This is a new subject that incorporates both theoretical and practical aspects that are needed to improve the 

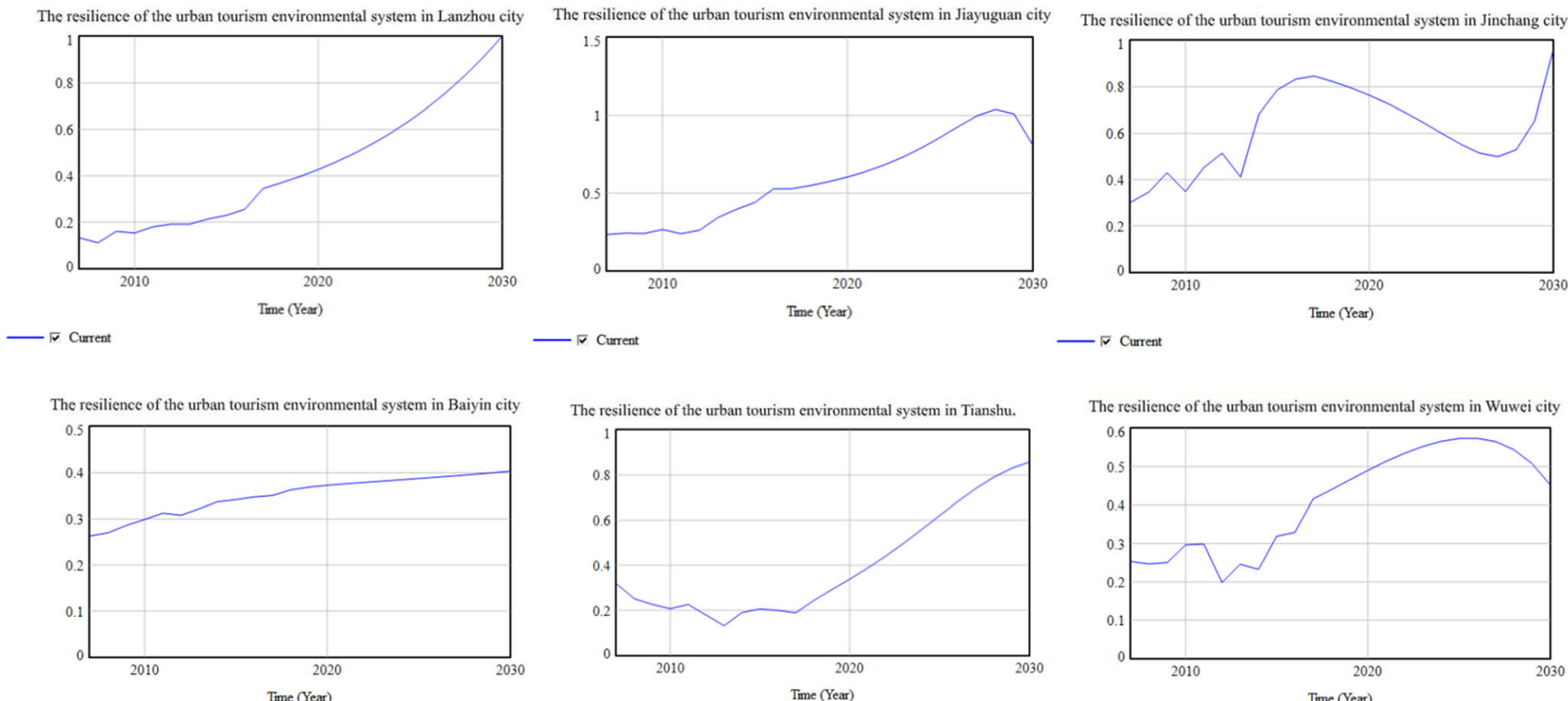

$\checkmark$ Current

- $v$ Current

- $\nabla$ Current

The resilience of the urban tourism environmental system in Zhangye city

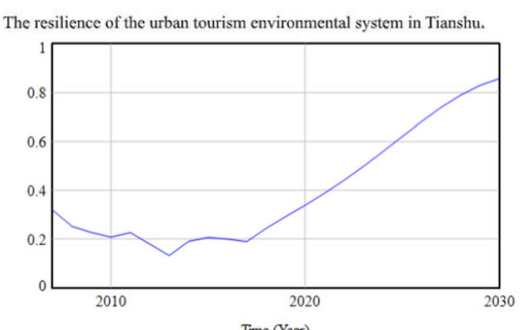

The resilience of the urban tourism environmental system in Wuwei city

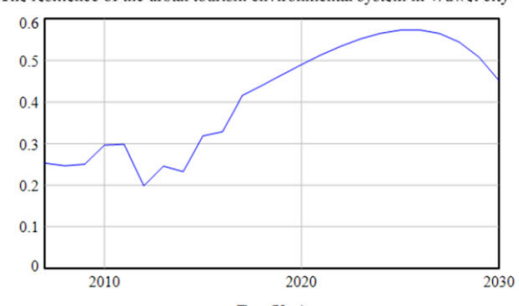

$\checkmark$ Current

The resilience of the urban tourism environmental system in Pingliang city

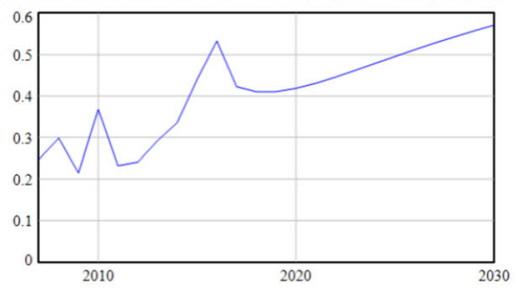

$\checkmark$ Current

The resilience of the urban tourism environmental system in Jiuquan city

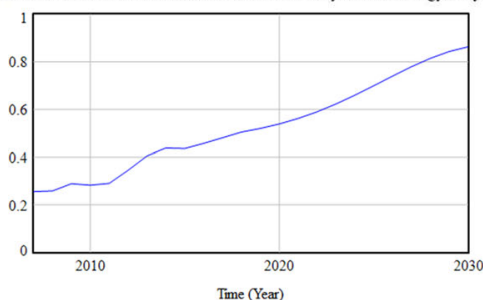

- $\nabla$ Current

Time (Year)

Time (Year)

- $v$ Current

The resilience of the urban tourism environmental system in Dingxi city

The resilience of the urban tourism environmental system in Qingyang city
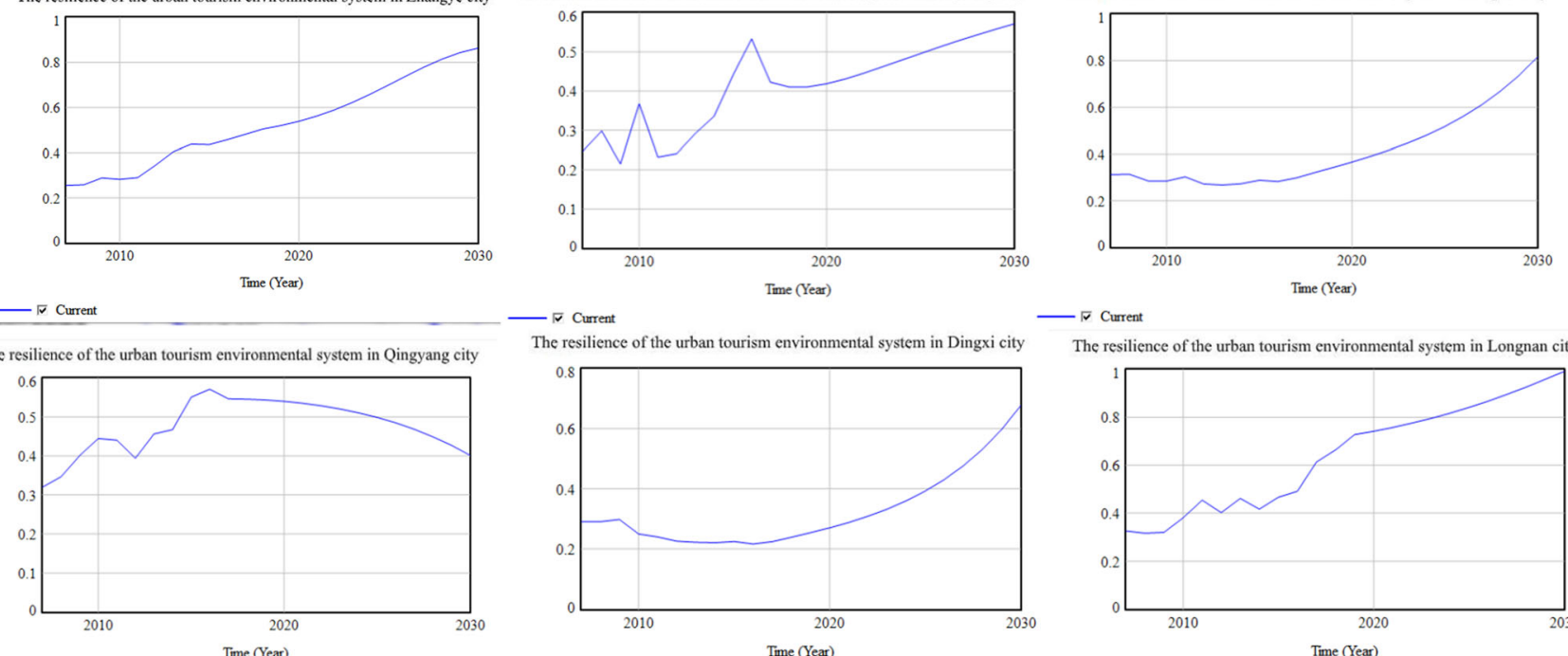

- $\sqrt{ }$ Current

The resilience of the urban tourism environmental system in Longnan city

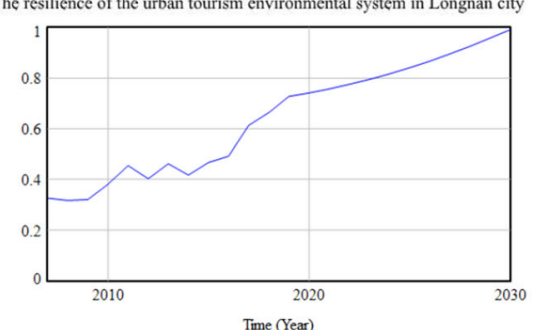

- $\nabla$ Current

$-\nabla$ Current

The resilience of the urban tourism environmental system in Linxia prefecture The resilience of the urban tourism environmental system in Gannan prefecture
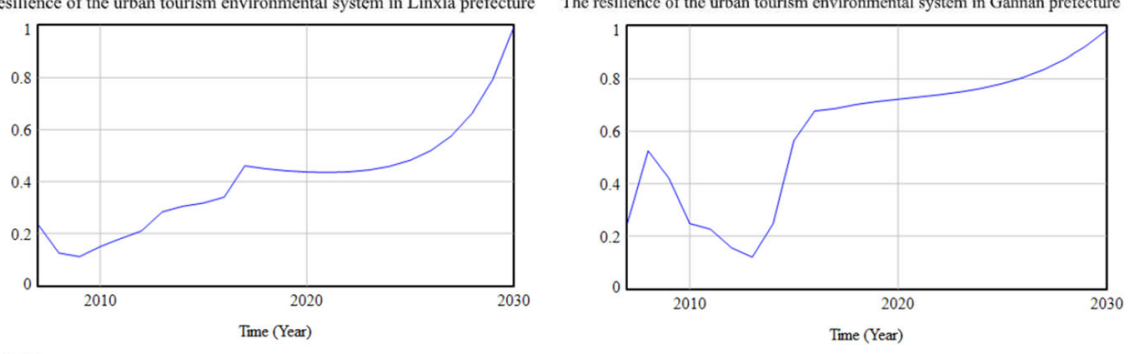

- V Current

- $\sqrt{ }$ Current

Fig. 13 Simulation results of resilience of UTES

response and adaptability of the destination tourism environment system in response to uncertainty, to improve the resilience of the destination tourism environment system, and to build a tourist city with Chinese tourism characteristics.

This paper takes regional cities as its geographical setting for the study of the resilience of the UTES, focusing on 14 cities of Gansu Province as examples to conduct positive research. It draws the following conclusions. First, the resilience level of UTES in Gansu Province shows fluctuations but nevertheless rises as a whole; the resilience of the UTES in these cities continues to improve while remaining very low overall. The development of the urban tourism economy is increasing 
The resilience of the urban tourism environmental system in Lanzhou city

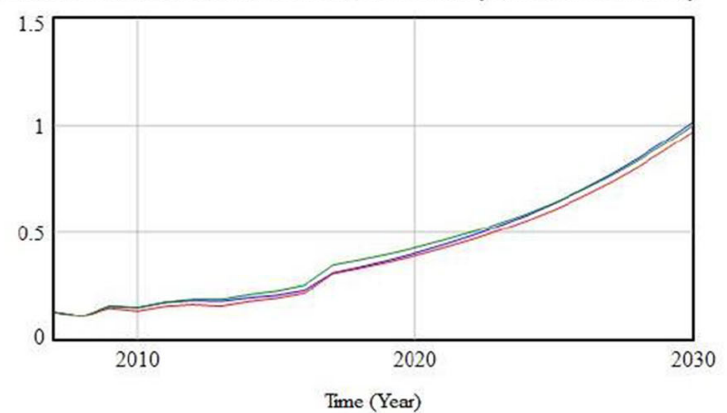

- $\checkmark$ Scenario 3 Sustainable development — $\square$ Scenario 1 Maintain the status quo - $\nabla_{\nabla}$ Scenario 2 Extensive development $\quad \Gamma$ Current

The resilience of the urban tourism environmental system in Jiayuguan city

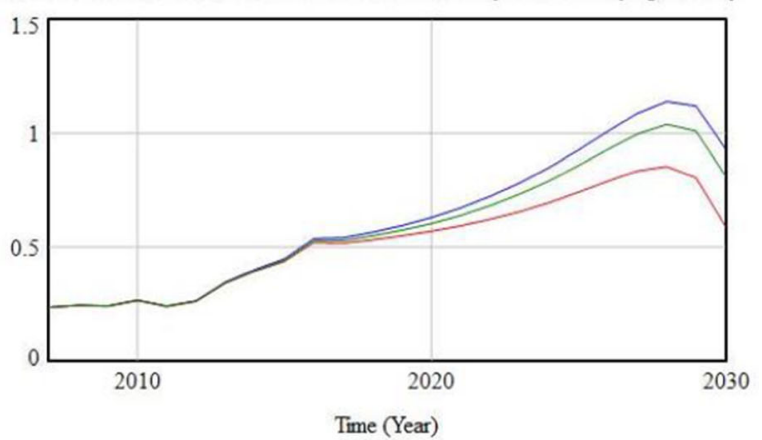

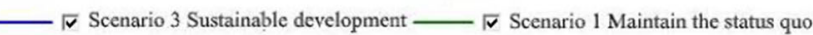
- $\checkmark$ Scenario 2 Extensive development

$\ulcorner$ Current

The resilience of the urban tourism environmental system in Baiyin city

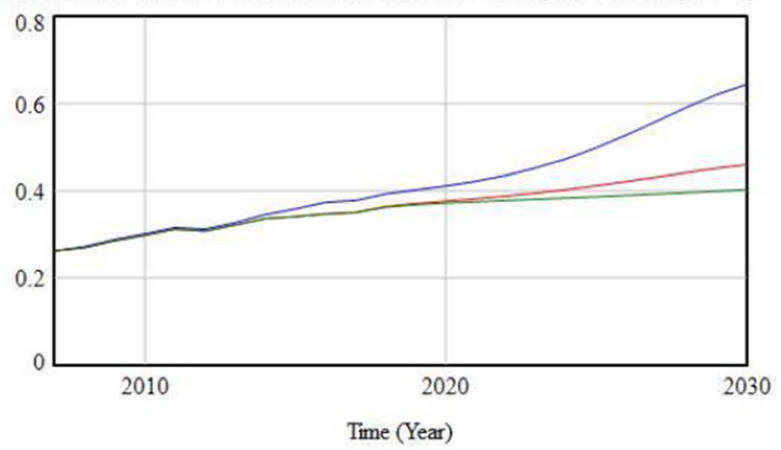

— Scenario 3 Sustainable development — $\square$ Scenario 1 Maintain the status quo $\square$ Scenario 2 Extensive development $\quad \Gamma$ Current

The resilience of the urban tourism environmental system in Zhangye city

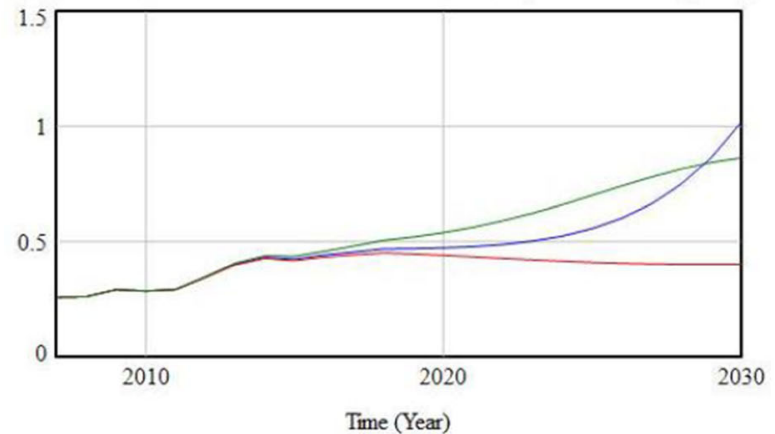

$\checkmark$ Scenario 3 Sustainable development $-\nabla$ Scenario 1 Maintain the status quo $\nabla$ Scenario 2 Extensive development $\quad\ulcorner$ Current

Fig. 14 Multi-scenario simulation results of UTES
The resilience of the urban tourism environmental system in Tianshui city

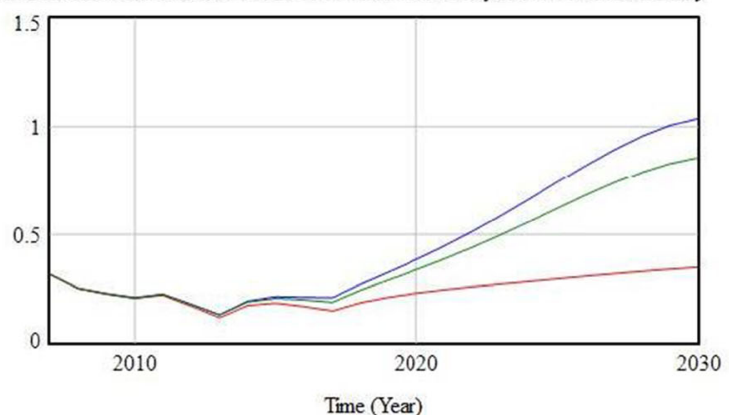

Time (Year)

- $\square$ Scenario 3 Sustainable development - $\nabla_{V}$ Scenario 2 Extensive development $\quad\ulcorner$ Current

The resilience of the urban tourism environmental system in Jinchang city

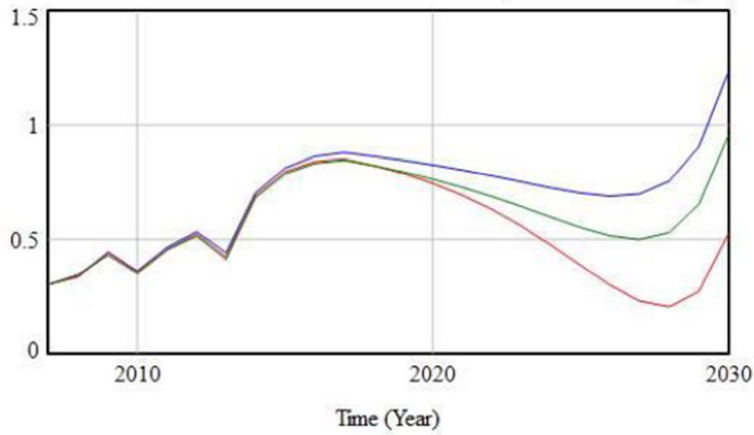

ॠ Scenario 3 Sustainable development $\square$ - Scenario 1 Maintain the status quo $\nabla$ Scenario 2 Extensive development $\quad \Gamma$ Current

The resilience of the urban tourism environmental system in Wuwei city

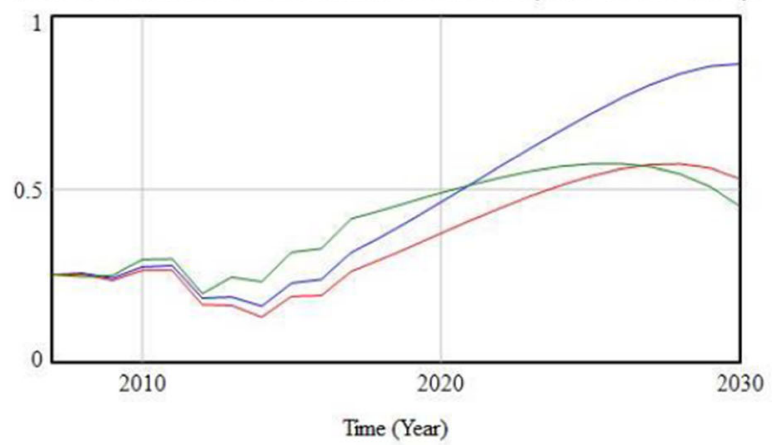

$\square$ Scenario 3 Sustainable development —— Scenario 1 Maintain the status quo $\nabla_{v}$ Scenario 2 Extensive development $\quad \Gamma$ Current

The resilience of the urban tourism environmental system in Pingliang city

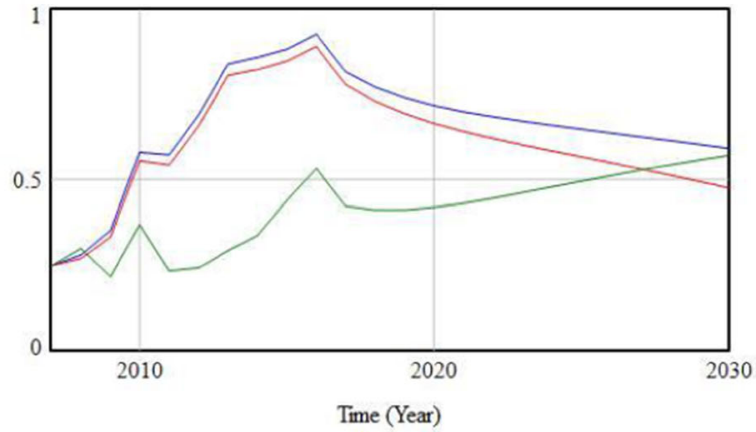

$\checkmark$ Scenario 3 Sustainable development _ $-\nabla$ Scenario 1 Maintain the status quo $\checkmark$ Scenario 2 Extensive development $\quad\ulcorner$ Current 
The resilience of the urban tourism environmental system in Jiuquan city
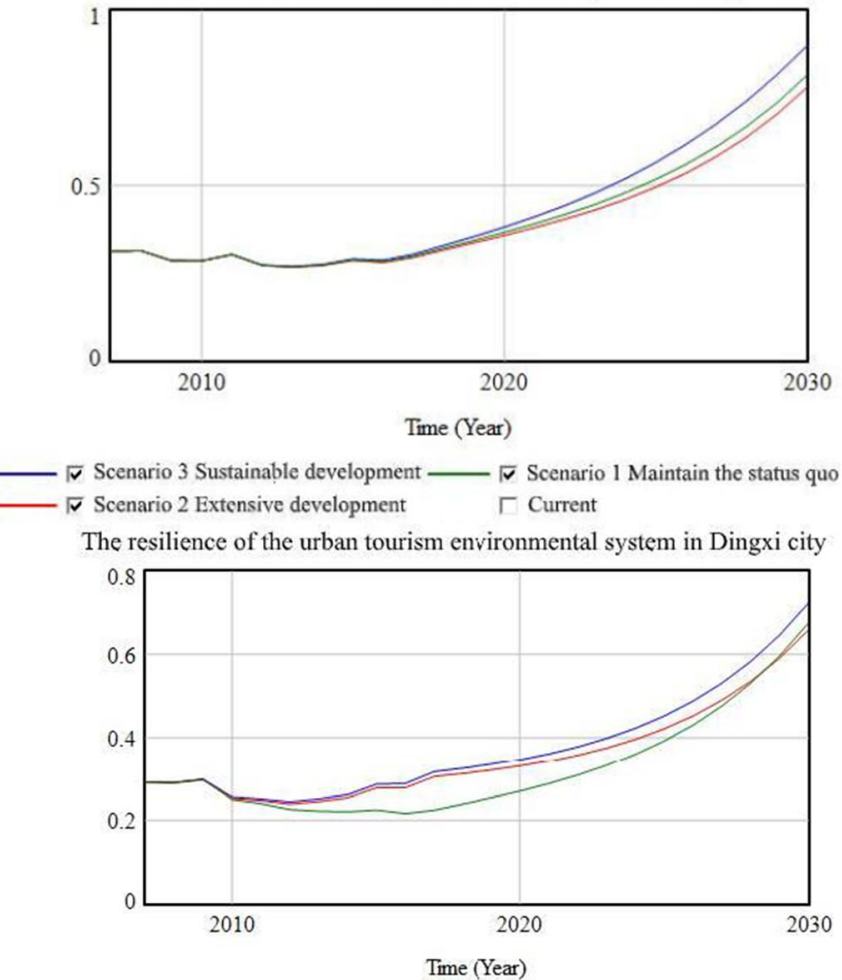

$\nabla_{\nabla}$ Scenario 3 Sustainable development $-\nabla_{\nabla}$ Scenario 1 Maintain the status quo - - Scenario 2 Extensive development

$\ulcorner$ Current

The resilience of the urban tourism environmental system in Linxia prefecture

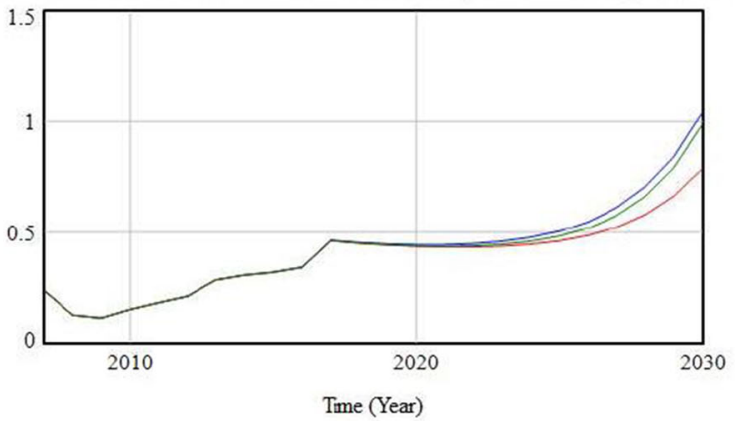

- $\checkmark$ Scenario 3 Sustainable development

$\sqrt{ }$ Scenario 1 Maintain the status quo IV Scenario 2 Extensive development

$\ulcorner$ Current
The resilience of the urban tourism environmental system in Qingyang city

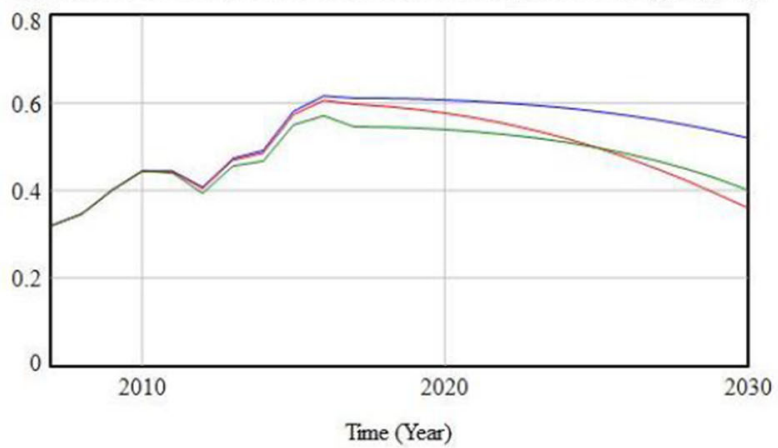

$\square$ Scenario 3 Sustainable development — $\square$ Scenario 1 Maintain the status quo - $\checkmark$ Scenario 2 Extensive development $\Gamma$ Current

The resilience of the urban tourism environmental system in Longnan city

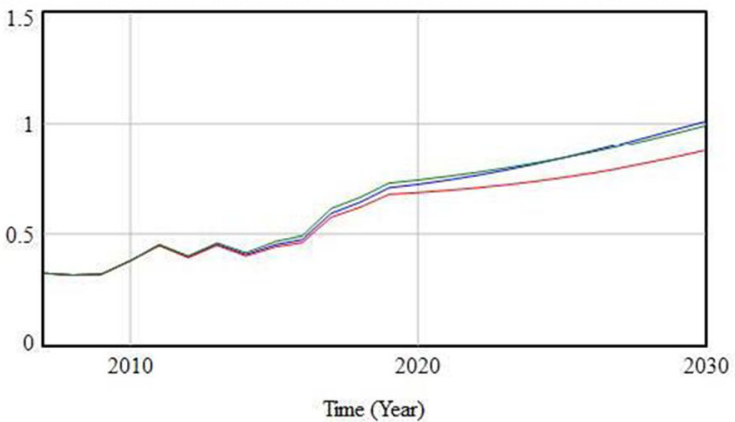

- $\nabla$ Scenario 3 Sustainable development — $-\nabla$ Scenario 2 Extensive development $\quad \Gamma$ Current

The resilience of the urban tourism environmental system in Gannan prefecture

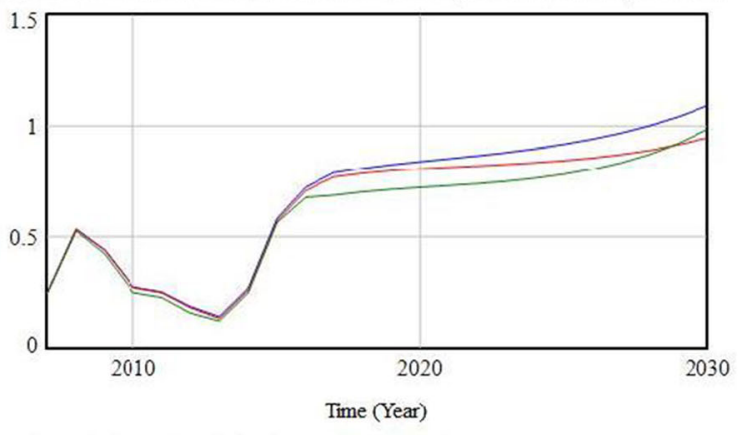

$\nabla$ Scenario 3 Sustainable development $\longrightarrow \nabla$ Scenario 1 Maintain the status quo $\nabla$ Scenario 2 Extensive development $\quad\ulcorner$ Current

Fig. 14 (continued)

pressure on the ecological environment. Second, the resilience of the UTES shows the following spatial distribution: high in the center, high in the northwest, and low in the southeast, with a spatial gap in the resilience of the UTES that tends to expand amid fluctuation. Third, the resilience of the UTES is both concentrated and dispersed spatially, and its center of gravity shows a shift to the northwest as a whole. Fourth, the SD simulation shows that the resilience of most UTES in Gansu Province show a fluctuating upward trend, and the use of sustainable development models can improve the resilience of such systems. To enhance the resilience of regional tourism environment systems, measures such as increasing regional urban tourism ecological environmental protection can be considered to achieve sustainable development, and improving urban infrastructure construction can be considered to boost tourism economic development. Further, optimizing the urban spatial layout to increase land use efficiency and narrowing the gap between the regional and urban-rural development to stimulate development vitality and enhance the resilience of the regional UTES can be pursued. 
The resilience of tourism environment system provides a new idea for urban sustainable development. The next step will be in the following areas:

Firstly, the connotation of urban tourism environment system resilience is deeply explored. Combined with the theory of resilience, the definition of tourism environment system resilience should be emphasized: the transition from a single determined goal to a dynamic goal. In view of the uncertainty of urban system risk, it is clear that the core of resilience of urban tourism environment system lies in real-time dynamic adjustment and adaptive balance. The tourism environment system is a comprehensive system from ordered features to complex chaos, and then to the adaptive ability in the context of differences from the perspective of multi-dimensional and multi steady state from planning guidance and control to urban governance, collaborative thinking and comprehensive path of urban governance are the means of implementation. Through the study of the connotation of the resilience of tourism environment system, it can promote the harmony of urban and build a theoretical research framework of resilience of regional tourism environment system.

Secondly, the mediation function of urban immersion area should be brought into play. Combined with the regional urban tourism development planning, the paper analyzes the sensitive factors of the resilience of the regional tourism environment system and calculates the potential of the tourism environment system. According to the scenario setting, the paper analyzes the actual utilization rate and immersion rate of the resilience of the tourism environment system and optimizes the solution of the resilience of the tourism environment system. Through the simulation of urban spatial expansion, overlay different scenarios and different states of the tourism environment system resilience security pattern, looking for more reasonable management tools, so as to achieve the purpose of effective regulation. Based on this, the paper classifies the status of the regional urban tourism environment system to restore the immersion area, transfers the pressure of the regional urban tourism environment, and promotes the co-construction and sharing of the regional urban tourism environment system.

Thirdly, pay attention to the empirical research. With the gradual enrichment of the theory of tourism environment system resilience, the practical research of urban resilience has been carried out. The future research focus is to explore the adaptability of quantitative model in different regional background, establish the governance framework of urban tourism environmental system resilience, improve the theoretical degree of research results, and explore and construct the basic theory of localization from the research of local characteristics. After the epidemic, we should promote China's development with urbanization, highlight the construction of sustainable development oriented resilience of tourism environment system, measure the comprehensive threshold of urban carrying capacity, explore the impact of risks on cities, and carry out urban cooperative governance based on the concept of sharing, Promote the high-quality development of regional urban tourism environment system.

Availability of data and materials The data sets used during the current study are available from the corresponding author on reasonable request.

Author contribution Xiuping Yang contributed to the conception of the study and analysis and manuscript preparation; Dacheng Zhang performed the experiment; Lili Liu performed the data analyses and wrote the manuscript; Jing Niu, Xiaobo Zhang, and Xiaoyun Wang helped perform the analysis with constructive discussions.

Funding This research was financially supported by the National Natural Science Foundation of China (Grant No. 41961020), the National Natural Science Youth Fund Project of China (Grant No. 41501597), the Ministry of Education "Chunhui Plan" Cooperative Scientific Research Project (GS2019002), Humanities and Social Sciences project of Gansu Province (20ZZ20) in 2020, Gansu Natural Science Fund Project (20JR10RA183), the Higher Education Innovative Ability Enhancement Project of Gansu Province (Grant No. 2019A-022), Lanzhou University of Technology Ph.D. Fund Project Funding, and Lanzhou University of Technology Hongliu First-class Discipline Support Direction "Management Decision Theory, Method and Application Construction Project." The roles of the funding body in this manuscript is providing the funds, make sure the research can successfully finished, including the design of the study and collection, analysis, and interpretation of data and in writing the manuscript.

Declarations We declare that we do not have any commercial or associative interest that represents a conflict of interest in connection with the work submitted. This paper has ethical approval. Ethical approval was obtained from the Chinese ethical research norms. We consent to publish and transfer of copyright.

Ethics approval and consent to participate Manuscripts reporting studies involving human participants, human data, or human tissue must:

- Have a statement on ethics approval and consent.

- Include the name of the ethics committee that approved the study and the committee's reference number ("not applicable" in this manuscripts).

- Studies involving animals must include a statement on ethics approval and for experimental studies involving client-owned animals; authors must also include a statement on informed consent from the client or owner ("not applicable" in this manuscripts).

Consent for publication We consent for publication for individual person's data in any form (including any individual details, images, or videos). All presentations of case reports have consent for publication.

Competing interests The authors declare no competing interests..

\section{References}

Amelung B, Student J, Nicholls S, Lamers M, Baggio R, BoavidaPortugal I, Johnson P, de Jong E, Hofstede GJ, Pons M, Steiger R, Balbi S (2016) The value of agent-based modeling for assessing 
tourism-environment interactions in the Anthropocene. Curr Opin Environ Sustain 23:46-53

Banerjee O, Boyle K, Rogers CT, Cumberbatch J, Kanninen B, Lemay M, Schling M (2018) Estimating benefits of investing in resilience of coastal infrastructure in small island developing states: an application to Barbados. Mar Policy 90:78-87. https://doi.org/10.1016/j. marpol.2018.01.004

Bangwayo-Skeete PF, Skeete RW (2020) Modelling tourism resilience in small island states: a tale of two countries. Tour Geogr 1:1-22. https://doi.org/10.1080/14616688.2020.1750684

Bramwell B (2010) Tourism development and the environment: beyond sustainability? Ann Tour Res 37:1194-1196. https://doi.org/10. 1016/j.annals.2010.07.003

Butler RW (1991) Tourism, environment, and sustainable development. Environ Conserv 18:201-209. https://doi.org/10.1017/ S0376892900022104

Calgaro E, Lloyd K, Dominey-Howes D (2014) From vulnerability to transformation: a framework for assessing the vulnerability and resilience of tourism destinations. J Sustain Tour 22:341-360. https:// doi.org/10.1080/09669582.2013.826229

Chen YL, Yang XJ (2011) Tourism social-ecological systems and resilience research. J Arid Land Resour Environ 25:205-211

Cheng Z, Jia TF (2020) Study on the coupling and coordination relationship between the structure of tourism flow network and tourism environment in Shanghai. Mod Urban Res 3:106-112

Cong XL, Huang Y, Liu JS (2019) Spatial and temporal evolution of coupled coordination degree of ecotourism environment of Jilin Province. Sci Geogr Sin 39:496-505

Dey J, Sakhre S, Gupta V, Vijay R, Pathak S, Biniwale R, Kumar R (2018) Geospatial assessment of tourism impact on land environment of Dehradun, Uttarakhand, India. Environ Monit Assess 190: 181. https://doi.org/10.1007/s10661-018-6535-4

Dharmawan NKS (2013) Tourism and environment: toward promoting sustainable development of tourism: a human rights perspective. Indones Law Rev 2:23-28. https://doi.org/10.15742/ilrev.v2n1.10

Dogru T, Marchio EA, Bulut U, Suess C (2019) Climate change: vulnerability and resilience of tourism and the entire economy. Tour Manag 72:292-305. https://doi.org/10.1016/j.tourman.2018.12.010

Erdmenger E (2019) Community Resilience in urban tourist destinations. Z Tourismuswissenschaft 11:437-450. https://doi.org/10.1515/tw2019-0025

Ghaderi Z, Mat Som APM, Henderson JC (2015) When disaster strikes: the Thai Floods of 2011 and tourism industry response and resilience. Asia Pac J Tourism Res 20:399-415. https://doi.org/10.1080/ 10941665.2014.889726

Guo YR, Zhang J, Zhang YL (2018) Influencing factor and mechanism of community resilience in tourism destinations. Geogr Res 37:133-144

Holladay PJ, Powell RB (2016) Social-ecological Resilience and stakeholders: a qualitative inquiry into community-based tourism in the commonwealth of dominica. Caribb Stud 44:3-28. https://doi.org/ $10.1353 / \mathrm{crb} .2016 .0000$

Holling CS (1973) Resilience and stability of ecological systems. Annu Rev Ecol Syst 4:1-23. https://doi.org/10.1146/annurev.es.04. 110173.000245

Ioannou A, Fuzuli G, Brennan F, Yudha SW, Angus A (2019) Multistage stochastic optimization framework for power generation system planning integrating hybrid uncertainty modelling. Energy Econ 80:760-776. https://doi.org/10.1016/j.eneco.2019.02.013

Jurigová Z (2016) Tourism: new destination of global business environment. Int Adv Econ Res 22:351-352. https://doi.org/10.1007/ s11294-016-9584-x

Katircioglu S, Cizreliogullari MN, Katircioglu S (2019) Estimating the role of climate changes on international tourist flows: evidence from Mediterranean Island States. Environ Sci Pollut Res 26:1439314399. https://doi.org/10.1007/s11356-019-04750-w
Kim JE, Park YJ, Lee JH, Tae-Woong K (2019) Socioeconomic vulnerability assessment of drought using principal component analysis and entropy method. J Korea Water Resour Assoc 52:441-449

Kushi E (2011) Sustainable tourism and environment protection in Albania. J Environ Prot Ecol 12:251-257

Larsen RK, Calgaro E, Thomalla F (2011) Governing resilience building in Thailand's tourism-dependent coastal communities: conceptualising stakeholder agency in social-ecological systems. Glob Environ Chang 21:481-491. https://doi.org/10.1016/j. gloenvcha.2010.12.009

Lee H, Baylon Verances JB, Song W (2009) The tourism-environment causality. Int J Tourism Sci 9:39-48. https://doi.org/10.1080/ 15980634.2009.11434617

Lew AA, He JM (2016) Scale GB, change and resilience in community tourism planning. Resour Sci 38:1635-1642

Made DA (2019) Dianasari L Tourism and the environment study of the implement of Green tourism concept in Jatiluwih tourism village, Bali-Indonesia. Conference on Tourism and Business.

Malliga S (2014) Tourism expenditures and environment in Thailand. Eurasian J Econ Fin 2:63-69

Marsiglio S (2015) Economic growth and environment: tourism as a trigger for green growth. Tour Econ 21:183-204. https://doi.org/ $10.5367 /$ te. 2014.0411

Middleton VTC, Hawkins R (2013) World Travel \& Tourism Environment Research Centre Oxford Brookes University, UK. Tour Rev 48:10-13

'Nikazachenko AL, Yudashkina EE, Vlasov GV, Novikova VV, Lebedev KA (2018) Modern approaches to assess tourism industry related environment. J Adv Res Manag 2:298-303

Ouattara B, Pérez-Barahona A, Strobl E (2019) Dynamic implications of tourism and environmental quality. J Public Econ Theor 21:241264. https://doi.org/10.1111/jpet.12330

Pavlovi S, Belij M, Vesi M, Jovanovic SS (2020) Improvement of the relationship between environment and tourism: case study of the National Park Derdap in Serbia. [Mittlungen der Osterrchischen Geographischen Gesellschaft] 1:251-270.

Shahgerdi A, Rezapouraghdam H (2016) The tourism-environment Nexus; challenges and opportunities. J Sustain Dev Stud 9:17-33

Singha K, Singha K (2012) Nexus between tourism and environment in Bhutan. Am J Tourism Manag 1:1-9

Solomitckii D, Koucheryavy Y, Semkin V, Karttunen A, Petrov V, Nguyen SLH, Nikopour H, Haneda K, Andreev S, Talwar S (2020) Characterizing radio wave propagation in urban street canyon with vehicular blockage at $28 \mathrm{GHz}$. IEEE Trans Veh Technol 69:1227-1236. https://doi.org/10.1109/TVT.2019.2959127

Strickland-Munro JK, Allison HE, Moore SA (2010) Using resilience concepts to investigate the impacts of protected area tourism on communities. Ann Tour Res 37:499-519. https://doi.org/10.1016/j. annals.2009.11.001

Wall G (2019) Contemporary studies in environment and tourism. J Ecotour 18:190-191. https://doi.org/10.1080/14724049.2018.1465256

Wang Q, Lu L, Yang XZ (2017) Cognition measurement and influence analysis of tourism community resilience: a case study of Qiandao Lake. Hum Geogr 5:139-146

Nabin B (2014) Evaluation and resilience of ecotourism in the Annapurnaconservation area, Nepal[J]. Environ Conser 41(1):84 92

Nancy AB, Caroline O, Jane ER, et al (2018) An integrative framework for investigating disaster resilience within the hotel sector[J]. J Hosp Tour Manag 36(9):67-75

Publisher's note Springer Nature remains neutral with regard to jurisdictional claims in published maps and institutional affiliations. 